\title{
UM SIMPLES MERCADO DE COMPRA E VENDA
}

\author{
Marilda Sotomayor*
}

\section{Resumo}

Modelamos um mercado de compra e venda como um jogo de mercado em que (a) todos os bens, exceto dinheiro, sāo idênticos e indivisíveis, (b) as preferências dos agentes podem ser descritas por um valor de reserva e (c) todos os compradores são tomadores de preços e podem comprar até uma dada cota de bens. Provamos que equilíbrios competitivos existem e sustentam alocações dos objetos para os compradores. Mais ainda, toda tal alocaçāo é sustentada por qualquer preço de equilíbrio. Resultados de estática comparativa sāo também obtidos. Reformulamos um mecanismo dinâmico de leilāo com preços ascendentes existente na literatura. Provamos que este mecanismo alcança o preço mínimo de equilíbrio num número finito de etapas e determinamos condiçōes para que ele seja nāo manipulável individualmente pelos compradores.

\section{Abstract}

We model a buying and selling market as a market game in which (a) all goods except money are identic and indivisible, (b) agents' preferences can be described by a reservation value, and (c) all buyers are price-takers and can buy up to their quota of goods. We prove that equilibrium prices exist and support efficient allocations of the goods to the buyers. Furthermore, every such allocation is supported by any equilibrium price. Results of comparative statics are also obtained. We reformulate a dinamic mechanism of auction existent in the literature and show that this mechanism yields the minimum competitive equilibrium in a finite number of steps. We obtain sufficient conditions under which this mechanism is individually non-manipulable by the buyers.

Palavras-Chave: Matching, equilíbrio de Nash; mecanismo.

Código JEL: C78 e D78.

"Universidade de Sāo Paulo, Departamento de Economia, Av. Prof. Luciano Gualberto 908, Cidade Universitária, 05508-900, Sāo Paulo. E-mail: marildas@usp.br.

R. de Econometria Rio de Janeiro v. 18, $\mathrm{n}^{2}$ 2, pp. 171-214 Novembro 1998 


\section{Introdução.}

O presente estudo, do qual este artigo é a primeira parte, oferece uma formalização, que não tem sido enfocada na literatura, para uma classe de jogos simples de mercado de dois lados: Um mercado de compra e venda, consistindo de um único vendedor interessado em vender vários objetos indivisíveis e idênticos e um conjunto de compradores, cada um dos quais está interessado em comprar até uma dada cota de objetos. Cada agente coloca um valor monetário sobre cada um dos objetos. Estes são os valores de reserva dos objetos para os agentes. O valor de reserva de um comprador pode ser pensado como a quantia máxima pela qual ele aceitaria comprar qualquer um dos objetos. $\mathrm{O}$ valor de reserva do vendedor representa o preço mínimo, pelo qual, ele aceitaria vender qualquer um dos objetos. Restringimo-nos ao caso mais simples, em que o valor de reserva de um comprador para um objeto não depende de quantos objetos ele obterá. Assim os valores de reserva dos objetos para um dado agente são iguais.

Uma interpretação para este mercado é a seguinte. $\mathrm{O}$ vendedor tem em mãos uma oferta de \$s para cada um dos objetos, proveniente de algum agente externo ao mercado, que comprará qualquer quantidade de objetos que lhe seja oferecida, por esse preço. Cada comprador $j$ (que pode ser pensado como um intermediário em vez de um consumidor final do objeto) tem em mãos uma oferta de $\$ a_{j}$, por objeto, de um cliente, que se compromete a comprar qualquer quantidade $k \leq r_{j}$ de objetos, se esta quantidade lhe for oferecida pelo comprador (por exemplo, o cliente possui uma agência de carros que só tem espaço para mais $r_{j}$ carros). Desde que o vendedor sabe que pode ganhar no mínimo \$s por objeto, ele não venderá nenhum objeto a um preço inferior a $\$ s$. Desde que cada comprador $j$ sabe que, comprando qualquer quantidade de objetos menor ou igual que $r_{j}$ (mas não mais) ele poderá revender todo o lote pelo preço de $\$ a_{j}$ 
cada unidade, ele não comprará nenhum objeto por um preço maior que $\$ a_{j}$ e não comprará mais do que $r_{j}$ objetos.

Assim se o vendedor vende $k_{j} \leq r_{j}$ objetos a cada comprador $j$, por $\$ p$ cada unidade, ele ganha $\$\left(k_{j} p\right)$ de cada comprador $j$; cada comprador $j$ ganha $\$ k_{j}\left(a_{j}-p\right)$.

A função do mercado é encontrar uma alocação factível: um matching e um preço factíveis. Um matching factível é uma alocação dos objetos para os compradores que aloca a cada comprador, no máximo, a sua cota de objetos e tal que cada objeto é alocado, no máximo, uma única vez. Um preço factível é um número que é maior ou igual ao preço de reserva do vendedor e é o mesmo para todos os objetos.

A condição de todos os objetos serem vendidos pelo mesmo preço é razoável, visto que existe um único vendedor e todos os objetos são idênticos. Entretanto existem situações economicamente naturais em que o vendedor discrimina, especificando diferentes preços para diferentes compradores. Esta é, por exemplo, a situação com que nos deparamos num mercado de trabalho. Aqui os vendedores são trabalhadores que vendem seus serviços às firmas, por salários. Cada trabalhador dispõe de uma cota de horas de trabalho por semana que ele poderá distribuir entre as várias firmas que por ventura o empregarem. Cada firma poderá contratar até uma certa cota de unidades de homens-hora de trabalho por semana. Um dado trabalhador pode ser contratado por diferentes firmas, por diferentes salários-hora. Mas dentro de uma mesma firma ele recebe o mesmo pagamento por cada hora de trabalho semanal. O nosso modelo corresponde ao caso em que o número de trabalhadores é igual a um. Neste caso os $a_{j}$ 's são o salário-hora máximo que a firma $j$ pagaria ao trabalhador. Naturalmente, o salário-hora mínimo que o trabalhador aceitaria para trabalhar numa dada firma poderia variar dependendo da ativiade que ele realizasse na firma. 
A regra do jogo de mercado é que qualquer comprador pode efetuar uma transação, juntamente com o vendedor, desde que ambos concordem; um comprador é livre de não comprar nenhum objeto e o vendedor é livre de não vender nenhum de seus objetos.

A pergunta econômicamente natural é: Que alocaçōes devemos esperar observar neste mercado?

Para responder a essa pergunta considere, por exemplo, um vendedor com dois objetos e dois compradores, $A$ e $B$, que estão interessados em comprar todos os objetos. Suponha que os valores de reserva dos compradores sejam $r_{A}=8$ e $r_{B}=6$. Suponha também que todos os tres agentes podem comunicar-se uns com os outros e que ofertas e contra ofertas sejam feitas, terminando com uma alocação factível. Podemos imaginar que uma transação entre um comprador e o vendedor ocorrerá somente quando ambos os agentes estiverem certos de que nada mais favorável existe para eles no mercado. Assim não podemos esperar que o vendedor venda algum objeto para o comprador $B$, pois o máximo que obteria seria 12. Neste caso a alocação não é Pareto eficiente e $A$ prefere comprar os dois objetos pagando por cada um deles o preço que $B$ está pagando, a deixar de comprar algum objeto. Assim $A$ sempre estaria disposto a pagar ao vendedor mais do que 12 comprando os dois objetos. Também não podemos esperar que o vendedor venda os dois objetos para $A$, cobrando por cada um deles um preço $p$ inferior a 6. Neste caso a alocação é eficiente mas $B$ prefere comprar os dois objetos pagando o preço que $A$ está pagando por eles a não comprar nenhum objeto. Assim $B$ teria interesse em comprar os dois objetos pagando ao vendedor um preço inferior a 6 mas superior a $p$ por cada um dos objetos. Dizemos que em nenhum dos dois casos a alocação é "livre de inveja".

Parece razoável esperar que somente alocações Pareto eficientes e livres de inveja ocorrerão. Na literatura, uma alocação Pareto 
eficiente e livre de inveja é chamada justa. O conceito solução que captura esta idéia de justiça é a de equilíbrio competitivo.

A existência de equilíbrios competitivos para este mercado é demonstrada no Teorema 1. Relembremos brevemente este conceito.

Um dado preço $p$ é um preço de equilıbrio competitivo se é factivel e se existe um matching factivel $x$ tal que (a) $p$ é o preço de reserva do vendedor se houver algum objeto não designado por $x$ $e$ (b) se $k$ objetos são designados a um comprador por $x$, então, dado $p$, nenhuma outra quantidade dará a este comprador um ganho total maior do que o que ele obtém com a quantidade $k$.

Neste caso dizemos que $(p, x)$ é um equilíbrio competitivo e que $x$ é compatível com $p$. (Dizemos também que $x$ é uma alocação de mercado sustentada por $p$ ).

Mostramos que se $(p, x)$ é um equilíbrio competitivo então $x$ é um matching ótimo e que todo matching ótimo é compatível com qualquer preço de equilíbrio. Informalmente, se $k$ objetos são designados a um comprador $j$ então o valor do par $(j, k)$ é $k$ vezes a diferença entre o valor de reserva de $j$ e o preço de reserva do vendedor. Dado um matching factível, a soma dos valores de tais pares é chamada de valor do matching. Um matching é ótimo (ou uma alocação dos objetos é eficiente) se ele tem o valor máximo dentre todos os matchings factíveis. É possível que em um matching ótimo alguns objetos não sejam alocados. Pode, também, existir mais de um matching ótimo. Isto ocorre quando dois ou mais compradores têm os mesmos valores de reserva. Por exemplo, se existem dois compradores, com cota 2 e valor de reserva igual a $V$, e dois objetos com preço de reserva menor que $V$, então é ótimo alocar um objeto para cada comprador ou alocar dois objetos para um deles e nenhum objeto para o outro. Nestes dois últimos casos dizemos que o matching ótimo é simples. (A definição precisa de um tal matching será dada no texto). 
Tendo sido demonstrado que preços de equilíbrio existem, observamos a existência de um preço mínimo (resp. máximo) de equilíbrio, que é o preço de equilíbrio menor (resp. maior) ou igual a qualquer outro preço de equilíbrio. Em seguida derivamos alguns resultados de estática comparativa, (Teorema 2) comparando os preços mínimo e máximo de equilíbrio antes e depois que novos compradores ou mais objetos entram no mercado. Embora esses resultados sejam bastante intuitivos as suas demonstrações não são tão simples e diretas.

O modelo considerado aqui é uma generalização do caso bem conhecido em que todos os compradores tem cota igual a um. Tem sido amplamente explorado na literatura de leilões de múltiplos objetos idênticos. Em geral se supõe que os compradores podem comprar todos os objetos ou que existe uma limitação sobre o número de objetos imposta pelo mercado, que é a mesma para cada comprador. Nos modelos de informação incompleta, costuma-se assumir que as avaliações dos compradores variam aleatória e continuamente num intervalo. Assim a existência de empate nos valores de reserva dos compradores tem probabilidade zero de ocorrer, o que implica na existência de somente um matching ótimo.

O nosso modelo é também relacionado com o jogo de designação múltipla (ver Sotomayor, 1992 e 1999-a e Crawford e Knoer, 1981). Num tal jogo cada comprador é designado a mais de um objeto, os objetos são distintos e cada objeto é associado a um vendedor e vice-versa. Portanto o jogo tem a estrutura de um mercado múltiplo, sendo no entanto tratado como um único mercado, em que os termos das parcerias comprador-vendedor são determinadas via negociações entre os parceiros potenciais. Assim, mesmo no caso em que os objetos têm o mesmo valor de reserva para os compradores, será razoável, algumas vezes, esperar preços distintos. Por exemplo, se existem dois objetos e somente um comprador cuja cota é 2 e cujos valores de reserva sejam iguais a 3 , então se os objetos têm preços 1 
e 2, por exemplo, o comprador quererá comprar os dois objetos. No nosso modelo esses preços não são considerados factíveis.

Tendo os equilíbrios competitivos sido caracterizados como as alocações que esperamos observar neste mercado, torna-se natural perguntar como obter esses resultados via um mecanismo simples de compra e venda. A idéia de usar equilíbrios competitivos como um mecanismo para fazer alocações com propriedades desejáveis de eficiência e justiça tem sido amplamente explorada na literatura. Demange (1982) e Leonard (1983) consideraram um mecanismo de alocação que é uma generalização do leilão de segundo preço de um único objeto para o caso de ítens distintos onde os compradores têm cota unitária. O leilão de segundo preço foi primeiro descrito por Vickrey (1961), para um mercado com um objeto. No leilão de Vickrey os compradores submetem lances lacrados para o objeto, que é vendido ao ofertante com o mais alto lance a um preço igual ao segundo maior lance. Podemos pensar no resultado do leilão de segundo preço como um equilíbrio competitivo ordinário. Ao dado preço, o objeto é demandado por somente um comprador, o de mais alto lance, e, como existe somente um objeto, isto produz balanço entre a oferta e a demanda. A importante propriedade do segundo lance mais alto é que ele é o preço mínimo de equilíbrio, desde que para qualquer preço menor ao menos dois ofertantes demandariam o objeto. Um resultado análogo é obtido para o modelo de mercado onde os objetos são idênticos e as cotas dos compradores são unitárias: se o número de objetos é $n$, o número de compradores é $m$, e $k=\min \{m, n\}$, então $k$ objetos são designados, um para cada um dos $k$ compradores com os $k$ mais altos valores. O preço de cada objeto é o $(n+1)$-ésimo valor mais alto, caso $n<m$ e 0 caso contrário.

O mecanismo de leilão de múltiplos objetos distintos e cota unitária de Demange (1982) e Leonard (1983) requer que cada ofer- 
tante submeta um lance lacrado listando sua avaliação para todos os ítens. O leiloeiro então designa os objetos de acordo com o preço mínimo competitivo. Estes artigos provam que a importante propriedade de compatibilidade de incentivos do leilão de Vickrey generaliza para o caso de múltiplos objetos, significando que declarar a verdadeira avaliação é uma estratégia dominante para os compradores. Mais geralmente (Demange e Gale, 1985), nenhum subconjunto de compradores pode, usando de não sinceridade na revelação de suas avaliações, melhorar o resultado para todos os seus elementos. (Ver Roth e Sotomayor, 1990).

Vários autores têm olhado para outros simples mecanismos de alocação que levam a equilíbrios competitivos. Dentre estes mecanismos encontram-se os leilões duplos, em que ambos compradores e vendedores agem estrategicamente. Em Demange e Gale (1985) é mostrado que se os vendedores podem manipular seus preços de reserva e o mecanismo produz o equilíbrio competitivo mínimo, os vendedores podem forçar o preço máximo de equilíbrio via equilíbrios de Nash, enquanto é uma estratégia dominante para os compradores revelar a verdade. Se o mecanismo produz o equilíbrio competitivo máximo, então é ótimo para os vendedores revelar seus verdadeiros preços de reserva enquanto os compradores podem forçar o preço mínimo de equilíbrio por equilíbrios de Nash.

Para o mercado de objetos idênticos e informação incompleta, A. Rustichini et al (1994) apresentam uma classe de leilões duplos que produzem preços de equilíbrio. Cada regra de leilão é definida por uma combinação convexa dos preços mínimo e máximo de equilíbrio. Neste mercado cada vendedor possui um único objeto e cada comprador deseja comprar, no máximo, um único objeto. Estes autores estabelecem resultados que podem classificar alguns dos mecanismos dessa classe de acordo com a rapidez com que a ineficiência esperada converge a zero. 
Entretanto, em vez de um leilão de lance lacrado com um único lance, é possível, em alguns casos, alcançar o preço mínimo de equilíbrio por um leilão dinâmico, num número finito de etapas. Este é o caso do mecanismo de Demange, Gale e Sotomayor (1986), desenhado para o caso de cota unitária e objetos distintos. É também o que ocorre na prática nos mercados com um único ítem, como por exemplo em Sothebys ou Park-Bernet, em que o leiloeiro sistematicamente sobe o preço de um ítem até que todos os ofertantes menos um deixem o leilão. Nestes leilões o preço de venda será aproximadamente o segundo lance mais alto desde que, presumivelmente, o ofertante de mais alto lance tentará ganhar a competição lançando a menor quantia possível.

Mostramos que essa propriedade é também compartilhada com o modelo que tratamos aqui. O leilão dinâmico que utilizamos é uma versão do mecanismo dinâmico padrão de leilão, de lances ascendentes, amplamente citado na literatura, cuja descrição resumida é como segue (ver, por exemplo, Ausubel (1997)):

"Para cada preço, $p$, anunciado pelo leiloeiro, cada comprador $j$ simultaneamente indica a quantidade $q_{j}(p)$ que ele deseja, onde é exigido que as demandas sejam não decrescentes no preço. Se a demanda agregada for maior do que o número de objetos leiloados, o preço é aumentado. Quando um preço $p^{*}$ é alcançado tal que a demanda agregada é menor ou igual ao número de objetos leiloados, o leilão termina. Cada comprador $j$ é então designado à $p_{j}(p)$ objetos e paga $p^{*}$ por cada objeto comprado".

O problema com esta descrição é que ela é pouco clara quanto ao que acontece quando o comprador é indiferente entre comprar ou não comprar o objeto. Por exemplo, considere que existem tres objetos e dois compradores, 1 e 2, com cota de 2, cada um. Suponha que o valor de reserva do comprador 1 é 8 e o valor de reserva do comprador 2 é 7 . Ao preço 6 , ambos os compradores demandam 2 objetos. A demanda agregada é 4, que é maior que o número total 
de objetos. Então o leiloeiro sobe o preço. Quando este preço chega a 7 o comprador 2 é indiferente entre não comprar nenhum objeto, comprar um objeto ou comprar dois objetos, pois qualquer destas alternativas lhe dá o mesmo payoff zero. Porém, se o jogador 2 deixa o mercado, o leiloeiro venderá dois objetos para o comprador 1 e terá um objeto não vendido, o que não é Pareto eficiente.

$\mathrm{Na}$ reformulação que propomos, o comprador 2 informa ao leiloeiro todas as suas op̧ões de demanda. Assim, no exemplo acima, o leiloeiro alocará eficientemente dois objetos para o comprador $1 \mathrm{e}$ um objeto para o comprador 2, pelo preço de 7 unidades. O resultado é o preço mínimo de equilíbrio para o mercado dado. ${ }^{1}$

Um outro problema ocorre quando o leiloeiro se depara com mais de uma escolha possível. O payoff dos compradores podem depender do matching escolhido pelo leiloeiro. Neste caso o jogo induzido pelo mecanismo não é bem definido. No leilão que propomos as regras do jogo incluem uma regra de desempate que o leiloeiro usará, quando necessário, e que será de conhecimento prévio por parte dos compradores. A reformulação geral é ilustrada no Exemplo 2.

\footnotetext{
${ }^{1}$ Ausubel (1997) propōe um leilāo ascendente para um mercado de objetos idênticos em que os compradores podem comprar mais de um objeto. A funçāo payoff de cada comprador é subaditiva. Assim sendo os preços dos objetos nāo necessitam ser os mesmos. Este leilāo se assemelha ao padrāo, com a diferença de que um comprador ganhador nāo necessariamente paga o preço final. Ele ilustra o seu leilāo com um exemplo no qual supōe que se um comprador é indiferente entre comprar e nāo comprar entāo ele nāo compra. Entretanto, com esta hipótese, nem sempre se terá alocaçōes eficientes como desejado. Para ilustrarmos o mecanismo de Ausubel suponha 3 objetos e 2 compradores limitados a comprar no máximo tres objetos. Seus valores sāo dados como segue. Comprador A: $v_{A, 1}=8, v_{A, 2}=v_{A, 3}=6$; comprador B: $v_{B, 1}=v_{B, 2}=v_{B, 3}=7$. Quando o preço atinge 6 o jogador $A$ é obrigado a reduzir a sua demanda para 1 unidade. Assim o comprador $\mathrm{B}$ garante ganhar dois objetos ao preço $p=6$ e demanda 3 objetos. Como a demanda agregada ainda é maior do que o número de objetos o leiloeiro aumenta o preç.o. Quando ó preço alcança 7 o jogador $B$ reduz sua demanda de 3 para 0 e o jogador $A$ demanda 1 objeto. Neste ponto 0 leilāo termina. $O$ jogador $B$ recebe 2 objetos ao preço 6 e o jogador $A$ recebe 1 objeto ao preço 7. Esta alocaçāo é claramente eficiente. Entretanto considere que a cota dos compradores agora é de 2 objetos e que $v_{A, 1}=8, v_{A, 2}=6 ; v_{B, 1}=v_{B, 2}=5$. Neste caso quando o preço atingir 5 o jogador $B$ reduzirá sua demanda de 2 para 0 ; o jogador $A$ receberá dois objetos por 5 e o leiloeiro ficará com um objeto sem vender. A alocaçāo resultante nāo é eficiente.
} 
É sabido que a importante propriedade de compatibilidade de incentivos de que são dotados os modelos de leilão de cota unitária, tanto com objetos idênticos como distintos, que produzem o preço mínimo de equilíbrio, não generaliza para o caso de cota geral e objetos distintos (ver Sotomayor (1992)). Que esta propriedade não é compartilhada pelo caso de objetos idênticos pode ser visto nos exemplos 1 e 2 deste trabalho. Entretanto se todos os compradores têm a mesma cota e o número de objetos é um múltiplo dessa cota ou é maior que o produto dessa cota pelo número de compradores, mostramos que a estratégia sincera é dominante para cada comprador. Isto significa dizer que, neste caso, o mecanismo de leilão considerado não é manipulável individualmente pelos compradores. (Este poderia ser o caso, por exemplo, em que as regras do leilão estipulassem uma mesma cota para cada comprador e houvesse um múltiplo desse número de objetos no mercado). As propriedades de que este mecanismo produz o preço mínimo de equilíbrio e é não manipulável individualmente pelos compradores, nas condições mencionadas acima, são demonstradas nos Teoremas 3 e 4, respectivamente. Os Exemplos 3 e 4 ilustram o fato de que nem sempre obteremos não-manipulabilidade individual por parte dos compradores quando as referidas condições forem violadas.

Fora o interesse teórico, pode ser de uso prático ter disponível o leilão dinâmico tanto como o de lance lacrado. Em particlar, o mecanismo de lance lacrado opera com a hipótese de que a utilidade de um ofertante é do tipo linear descrito aqui, mas este é um caso bastante especial. O mecanismo dinâmico permite uma gama mais ampla de preferências para os ofertantes. Os resultados dados aqui sugerem que para lances suficientemente pequenos nosso leilão produz preços que se aproximam arbitrariamente do preço mínimo de equilíbrio. Porém, nossos resultados são dados somente para o caso linear. A análise para preferências mais gerais permanece um problema para investigação futura. 
A idéia de produzir alocaçoes competitivas via um jogo não cooperativo foi também usada em Wilson (1977), mas numa abordagem diferente da apresentada aqui. Este artigo considera uma economia de troca com bens divisíveis, em que as negociações são organizadas como um jogo de lances. Sob várias hipóteses de regularidade (que não se aplicam ao nosso modelo) é mostrado que este jogo tem um equilíbrio que produz uma alocação do núcleo do correspondente jogo cooperativo de troca. Os compradores são replicados e no limite esta alocação do núcleo é um equilíbrio competitivo.

O presente trabalho é organizado como segue. Na seção 2 descrevemos o modelo cooperativo. A seção 3 trata dos matchings ótimos. Na seção 4 mostramos a existência de preços de equilíbrio. Provamos que os preços de equilíbrio são compatíveis com qualquer matching ótimo e que os matchings ótimos são compatíveis com qualquer preço de equilíbrio. A seção 5 é devotada aos resultados de estática comparativa. Na seção 6 descrevemos o mecanismo de leilão dinâmico e provamos que ele produz o preço mínimo de equilíbrio. A seção 7 trata da manipulabilidade deste mecanismo por parte dos compradores. A seção 8 conclui o trabalho.

\section{Modelo Cooperativo Formal.}

Existem $m$ compradores: $1,2, \cdots, m$ e $n$ objetos indivisíveis e idênticos. O conjunto de compradores será denotado por $P$ e um comprador genérico por $j$ ou $k$. O conjunto de objetos será denotado por $Q$ e um objeto genérico por $q$. O valor de cada objeto para o comprador $j$ é $a_{j} \geq 0$. Cada comprador tem uma cota $r_{j}$, representando o número máximo de objetos que está interessado em comprar, onde $r_{j}$ é um número inteiro maior ou igual a zero. Normalizando, consideraremos que o preço de reserva de cada objeto para o vendedor é 0 . Assim o mercado é dado por $M=(P, Q, r, a)$. 
Definição 1: Um matching factivel para $M=(P, Q, r, a)$ é um vetor $x=\left(x_{1}, \cdots, x_{m}\right)$ de coordenadas inteiras não negativas tais que $\sum_{j \in P} x_{j} \leq n$ e $x_{j} \leq r_{j}$.

Se $x_{j}=c$ ( $c$ pode ser zero) diremos que $c$ objetos são designados para o comprador $j$ pelo matching $x$ ou que o comprador $j$ compra $c$ objetos segundo $x$. Se um matching $x$ é factível então segue da definição 1 que $\sum_{\mathbf{j} \in \mathbf{P}} \mathrm{x}_{\mathbf{j}} \leq \min \left\{\mathbf{n}, \sum_{\mathbf{j} \in \mathrm{P}} \mathrm{r}_{\mathbf{j}}\right\}$.

Definição 2: Um preço factivel é qualquer número real $p \geq 0$.

O par $(p, x)$ onde $p$ é um preço factível e $x$ é um matching factível é chamado de alocação factível. Se o comprador $j$ compra $c$ objetos pelo preço $p$ então o seu payoff total será $c\left(a_{j}-p\right)$. Neste caso dizemos também que $(p, x)$ aloca $c$ objetos para $j$ ao preço $p$.

Definição 3: $O$ conjunto de demanda de $j$ ao preço $p$, que será denotado por $D_{j}(p)$, é dado por

$$
\begin{aligned}
D_{j}(p)=\left\{c \text { inteiro } 0 \leq c \leq r_{j} \text { e } c\left(a_{j}-p\right) \geq c^{\prime}\left(a_{j}-p\right) \forall c^{\prime}\right. \\
\\
\text { com } \left.0 \leq c^{\prime} \leq r_{j}\right\} .
\end{aligned}
$$

Consequentemente,

$$
\begin{aligned}
& D_{j}(p)=\left\{r_{j}\right\} \quad \text { se } \quad a_{j}>p ; \\
& D_{j}(p)=\left\{0,1,2, \cdots, r_{j}\right\} \quad \text { se } \quad a_{j}=p \text { e } \\
& D_{j}(p)=\{0\} \quad \text { se } \quad a_{j}<p .
\end{aligned}
$$

$D_{j}(p)$ é o conjunto das quantidades de objetos que maximizam o payoff total de $j$ ao preço $p$. Portanto $j$ é indiferente entre duas quaisquer quantidades demandadas. Assim, por exemplo, se existem 
dois ou mais objetos no mercado, o comprador $j$ tem cota igual a 2 e avalia cada objeto em 3 unidades monetárias, ele demandará dois objetos ao preço $p^{1}=1$, que lhe dará um payoff total de $2(3-1)=4$. Qualquer quantidade inferior a 2 que seja alocada para $j$ produzirá um payoff total menor que 4 e qualquer quantidade $k$ superior a 2 produzirá um payoff total de $4-(k-2)<4$, visto que $k-2$ objetos serão comprados ao preço $p^{1}=1$ e não lhe serão de utilidade, pois sua cota é 2. Ao preço $p^{2}=3$ o comprador $j$ poderá demandar nenhum, 1 ou 2 objetos. Em qualquer alternativa terá um payoff total de zero. Ao preço $p^{3}=4$ o payoff máximo será 0 , que ocorrerá se o comprador demandar 0 objeto, pois qualquer outra quantidade lhe dará um payoff negativo.

Definição 4: $O$ preço $p$ é chamado competitivo se existe um matching factivel $x$ tal que $x_{j} \in D_{j}(p)$, para todo comprador $j$. Neste caso $x$ é dito ser compativel com $p$.

Assim, dado um preço competitivo, cada comprador pode comprar alguma quantidade demandada por ele ao preço dado.

Definição 5: $A$ alocação $(p, x)$ é um equilıbrio competitivo se $p$ é competitivo, $x$ é compativel com $p$ e além disso $p=0$ se houver algum objeto não vendido. Se $(p, x)$ é um equilibrio competitivo então $p$ é chamado de preço de equilibrio e $x$ é chamado matching competitivo.

Assim, a preços competitivos, não somente todo comprador obtém uma quantidade de objetos do seu conjunto de demanda, mas também nenhum objeto não vendido tem um preço superior ao seu preço de reserva, posto que se existir algum objeto não vendido então todos os preços são iguais ao preço de reserva. 


\section{Matchings Ótimos.}

Considere $a_{1}, \cdots a_{1}, a_{2}, \cdots a_{2}, \cdots, a_{m}, \cdots, a_{m}$, uma ordenação dos valores de reserva dos compradores onde cada cada $a_{j}$ é repetido $r_{j}$ vezes. Um matching ótimo associa os $K$ objetos com os $K$ primeiros valores da ordenação, onde $K=\min \left\{n, \sum_{j \in P} r_{j}\right\}$. Esta ordenação pode não ser única no caso em que há empates nos valores de reserva dos compradores. Nestes casos várias outras formas de ordenar esses valores podem ser consideradas para se conseguir um matching ótimo. Por exemplo, se existem 3 compradores, cada um com cota $2, a_{1}>a_{2}=a_{3}$, e existem 4 objetos, então se considerarmos a ordenação $a_{1}, a_{1}, a_{2}, a_{3}, a_{3}, a_{2}$, alocaremos os 4 objetos para os 4 primeiros valores, obtendo-se o matching $x=(2,1,1)$. Existem outros matchings ótimos para este mercado: $(2,2,0)$ e $(2,0,2)$. Por razōes técnicas nos concentraremos nos matchings ótimos em que há, no máximo, um comprador que recebeu algum objeto e não preencheu a sua cota, como os dois últimos do exemplo acima. Esta restrição equivale a considerar apenas os matchings ótimos que pertencem a uma classe especial de matchings que chamaremos de simples. A definição de um matching simples é dada na Definição 7 abaixo. A Proposição 1 implica que se $x$ é um matching ótimo então ou todos os compradores preenchem a sua cota ou não existem objetos não vendidos. A Proposição 2 caracteriza os matchings ótimos dentro do conjunto dos matchings simples. A Proposição 3 caracteriza os matchings simples dentro do conjunto dos matchings ótimos. Formalmente um matching ótimo é:

Definição 6: $O$ matching $x$ é ótimo para o mercado $M$ se é factivel e $\sum_{j} a_{j} x_{j} \geq \sum_{j} a_{j} x_{j}^{\prime}$ para todo matching factivel $x^{\prime}$.

O valor de um matching $x$ é o número $\sum_{j} a_{j} x_{j}$. Portanto $x$ é ótimo se, dentre todos os matchings factíveis, possui o maior valor. Como o número de alocaçōes factíveis é finito, existe sempre, no 
mínimo, um matching ótimo. Para ilustrar este conceito considere o seguinte exemplo.

Exemplo 1: O mercado é dado por $P=\{1,2,3\}, Q$ com 3 objetos, $r_{j}=2$ para todo $j=1,2,3$ e $a=(5,8,3)$. O único matching ótimo é $x=(1,2,0)$, cujo valor é $a_{1}+2 a_{2}=5+16=21$.

Observação 1: Se existir algum objeto não designado e algum comprador $j$ que não tenha preenchido sua cota num matching factível, com $a_{j}=0$, então se alocarmos o objeto para $j$ não alteramos o valor de $x$. Assim sendo, não perderemos nada em assumir que, sempre que existir algum objeto não alocado a nenhum comprador por um matching factível, então todo comprador $j \operatorname{com} a_{j}=0$ terá preenchido sua cota segundo este matching.

Reindexe, se necessário, os compradores de tal forma que os $a_{j}$ 's possam ser ordenados em ordem decrescente: $a_{1} \geq a_{2} \geq a_{3} \geq a_{4} \geq$ $\cdots \geq a_{m}$.

Definição 7: $O$ matching $x$ é simples para a ordenação $\left(a_{1}, a_{2}, a_{3}, a_{4}, \cdots, a_{m}\right)$ se é factivel $e \forall j, k \in P$, com $a_{j}=a_{k}$ e $j<k$, tem-se que $x_{j}=\min \left\{r_{j}, x_{j}+x_{k}\right\}$. O matching $x$ é simples se é simples para alguma ordenação dos $a_{j}$ 's.

Por exemplo, se $a_{1}=6, a_{2}=7, a_{3}=8, a_{4}=7$ temos duas ordenaçōes possíveis: $\left(a_{3}, a_{4}, a_{2}, a_{1}\right)$ e $\left(a_{3}, a_{2}, a_{4}, a_{1}\right)$. Suponha que existam 4 objetos no mercado e que cada comprador tenha cota 2 . Então o matching $x_{1}=0, x_{2}=1, x_{3}=2, x_{4}=1$ é ótimo mas não é simples. O matching $x_{1}^{\prime}=1, x_{2}^{\prime}=2, x_{3}^{\prime}=1, x_{4}^{\prime}=0$ é simples para a segunda ordenação mas não é ótimo. Os únicos matchings ótimos e simples são: $y_{1}=0, y_{2}=0, y_{3}=2, y_{4}=2$ e $y_{1}^{\prime}=0, y_{2}^{\prime}=2, y_{3}^{\prime}=2$, $y_{4}^{\prime}=0$. 
Decorre da Definição 7 que se $x$ é simples e $a_{j}=a_{k} \operatorname{com} j<k$ e $x_{j}<r_{j}$ então $x_{j}=x_{j}+x_{k}$, donde $x_{k}=0$. Consequentemente se $x_{k}>0$ então $x_{j}=r_{j}$.

Observação 2: Dado um matching factível $x$, existe um matching simples $x^{\prime}$, para $\left(a_{1}, \cdots, a_{m}\right)$, tal que $x$ e $x^{\prime}$ possuem o mesmo valor. De fato, defina

$$
\begin{aligned}
& x_{j}^{\prime}=x_{j} \quad \text { se } \quad a_{j} \neq a_{k}, \quad \forall k \in P \\
& \text { se } a_{j}=a_{j+1}=\cdots=a_{j+t} \text { para algum } t \geq 1, \text { e } a_{j-1}>a_{j} \\
& \text { se } j \geq 2 \text { e } a_{j+t}>a_{j+t+1} \text { se } j+t<m, \text { então } \\
& x_{j}^{\prime}=\min \left\{r_{j}, x_{j}+x_{j+1}+\cdots+x_{j+t}\right\} \\
& \text { e } \forall s=1, \cdots, t: \\
& x_{j+s}^{\prime}=\min \left\{r_{j+s},\left(x_{j}+\cdots+x_{j+t}\right)-\left(x_{j}^{\prime}+\cdots+x_{j+s+1}^{\prime}\right)\right\} .
\end{aligned}
$$

Isto é, os objetos são alocados de tal forma que $j+s$ recebe algum objeto somente se $j+s-1$ preencheu a sua cota, $\forall s=1, \cdots, t$. Temos também que $x_{j}^{\prime}+\cdots+x_{j+t}^{\prime}=x_{j}+\cdots+x_{j+t}$. Por construção segue que $x^{\prime}$ é simples e tem o mesmo valor de $x$.

Proposição 1: Seja $x$ um matching ótimo. Então $\sum_{j} x_{j}=$ $\min \left\{n, \sum_{j} r_{j}\right\}$.

Demonstração: Decorre da Definição 1 que $\sum_{j} x_{j} \leq$ $\min \left\{n, \sum_{j} r_{j}\right\}$. Então suponha que $\sum_{j} x_{j}<\min \left\{n, \sum_{j} r_{j}\right\}$. Isto significa que $\sum_{j} x_{j}<n$ e $\sum_{j} x_{j}<\sum_{j} r_{j}$, o que implica que existe, no mínimo, um objeto não alocado e, no mínimo, um comprador $j$ que não preencheu sua cota. Pela observação 1 temos que $a_{j}>0$. Então podemos construir um matching $x^{\prime}$ com valor maior do que o valor de $x$, dando a $j$ mais um objeto, um dos objetos que não estavam alocados a ninguém, contradizendo a otimalidade de $x$.

Revista de Econometria 18 (2) Novembro 1998 
Proposição 2: Seja $x$ um matching simples para a ordenação $\left(a_{1}, \cdots, a_{m}\right)$. O matching $x$ é ótimo se e somente se (a) $\forall j, k$ com $j<k$, se $x_{j}<r_{j}$ então $x_{k}=0$ (consequentemente $\forall j, k$ com $j<k$, se $x_{k}>0$ então $x_{j}=r_{j}$ ) e (b) $\sum_{j} x_{j}=\min \left\{n, \sum_{j} r_{j}\right\}$.

Demonstração: Suponha que $x$ é ótimo. Para provar (a) seja $j<k$ com $x_{j}<r_{j}$. Considere primeiro que $a_{j}>a_{k}$. Então suponha por absurdo que $x_{k}>0$. Considere $x^{\prime}$ tal que $x_{p}^{\prime}=x_{p}$ se $p \in P-\{j, k\}$, $x_{k}^{\prime}=x_{k}-1$ e $x_{j}^{\prime}=x_{j}+1$. Este novo matching é factível pois o número de objetos designados a qualquer comprador diferente de $j$ e $k$ não foi alterado, o número total de objetos designados ao conjunto $\{j, k\}$ não foi alterado, $j$ não completou a sua cota em $x$ e portanto pode receber mais um objeto e $k$ pode receber menos um objeto sem o perigo de receber um número negativo de objetos, visto que recebera originalmente $x_{k}>0$. Então, usando que $a_{j}>a_{k}$, obtemos que $a_{j} x_{j}^{\prime}+a_{k} x_{k}^{\prime}=\left(a_{j} x_{j}+a_{k} x_{k}\right)+\left(a_{j}-a_{k}\right)>a_{j} x_{j}+a_{k} x_{k}$. Portanto, $\sum_{p} a_{p} x_{p}^{\prime}>\sum_{p} a_{p} x_{p}$, contradizendo a otimalidade de $x$. Considere agora que $a_{k}=a_{j}$. Como $x_{j}<r_{j}$ e $x$ é simples para $\left(a_{1}, \cdots, a_{m}\right)$, segue que $j$ recebeu a quantidade total de objetos que $x$ distribuiu ao conjunto $\{j, k\}$, donde $x_{k}=0$.

A parte (b) segue da Proposição 1. Na outra direção, suponha que o matching $x$ satisfaz (a) e (b). Queremos mostrar que ele é ótimo. Suponhamos que não. Seja $x^{\prime}$ um matching ótimo e simples. A otimalidade de $x^{\prime}$ implica que $\sum_{j} a_{j} x_{j}<\sum_{j} a_{j} x_{j}^{\prime}$, donde existe $k$ tal que $a_{k} x_{k}<a_{k} x_{k}^{\prime}$, donde segue que

$$
0 \leq x_{k}<x_{k}^{\prime} \leq r_{k},
$$

e portanto $x_{k}<r_{k}$ e $x_{k}^{\prime}>0$. Por conseguinte $x_{j}=0$ para todo $j>k$, por (a). Por outro lado, segue da parte já demonstrada que $x^{\prime}$ satisfaz (a). Então, como $x_{k}^{\prime}>0$, temos que $x_{j}^{\prime}=r_{j}$ para todo $j<k$. Como $x$ e $x^{\prime}$ satisfazem (b), temos que $\sum_{j} x_{j}=\sum_{j} x_{j}^{\prime}=$ $\min \left\{n, \sum_{j} r_{j}\right\}$. Assim sendo decorre que $\sum_{j<k} x_{j}+x_{k}=\sum_{j} x_{j}=$ 
$\sum_{j} x_{j}^{\prime}=\sum_{j<k} r_{j}+\sum_{j>k} x_{j}^{\prime}+x_{k}^{\prime} \geq \sum_{j<k} x_{j}+\sum_{j>k} x_{j}^{\prime}+x_{k}^{\prime}$. Logo, $x_{k} \geq \sum_{j>k} x_{j}^{\prime}+x_{k}^{\prime} \geq x_{k}^{\prime}$, e portanto $x_{k} \geq x_{k}^{\prime}$, que contradiz (1). Portanto $x$ é ótimo e a demonstração está completa.

Observação 3: Se $x$ é ótimo e simples para a ordenação $\left(a_{1}, \cdots, a_{m}\right)$, então decorre da Proposição 2 que existe $k \in P$ tal que $x_{j}=r_{j} \forall j<$ $k, x_{j}=0 \forall j>k$ e $x_{k}=n-\sum_{j \neq k} x_{j}$. Existe portanto um único matching ótimo que seja simples para a ordenação $\left(a_{1}, \cdots, a_{m}\right)$. Num tal matching existe, no máximo, um comprador que recebeu algum objeto e não preencheu a sua cota em $x$.

Observe que na demonstração da Proposição 2 provamos que se $a_{j}>a_{k}$ e $x_{j}<r_{j}$ então $x_{k}=0$, usando apenas a otimalidade de $x$. Portanto:

Corolário 1: Seja $x$ um matching ótimo. Sejam $j, k \in P$ tais que $a_{j}>a_{k}$. Então se $x_{j}<r_{j}$ devemos ter que $x_{k}=0$.

Proposição 3: Seja $x$ um matching ótimo. Então existe no máximo um comprador que não preencheu a sua cota e recebeu algum objeto se e somente se $x$ é simples.

Demonstração: Já sabemos da Observação 3 que se $x$ é simples então existe, no máximo, um comprador que não preencheu sua cota e recebeu algum objeto. Para provar a outra direção considere a ordenação $\left(a_{1}, \cdots, a_{m}\right)$ onde se $a_{j}=a_{k}, x_{j}<r_{j}$ e $x_{k} \neq 0$, então $k<j$. Consequentemente se $a_{j}=a_{k}, x_{j}<r_{j}$ e $j<k$ então $x_{k}=0$. Esta ordenação está bem definida, desde que existe no máximo um comprador $j$ com $0<x_{j}<r_{j}$.

Agora suponha que existam $j$ e $k \operatorname{com} a_{j}=a_{k}$ e $j<k$. Devemos mostrar que $x_{j}=\min =\left\{r_{j}, x_{j}+x_{k}\right\}$. Temos de analisar dois casos.

10 caso: $j$ completou sua cota ou não recebeu nenhum objeto. (i.e., $x_{j}=r_{j}$ ou $x_{j}=0$ ). Se $x_{j}=0$ temos, pela construção da

Revista de Econometria 18 (2) Novembro 1998 
ordenação $\left(a_{1}, \cdots, a_{m}\right)$, que $x_{k}=0$. Assim, em ambos os casos, $x_{j}=\min \left\{r_{j}, x_{j}+x_{k}\right\}$.

2 Q caso: $j$ recebeu algum objeto mas não completou sua cota. (i.e., $0<x_{j}<r_{j}$ ). Neste caso segue da construção da ordenação $\left(a_{1}, \cdots, a_{m}\right)$ que $x_{k}=0$. Portanto, $x_{j}=\min \left\{r_{j}, x_{j}+x_{k}\right\}$.

Temos assim provado que $x$ é simples para a ordenação $\left(a_{1}, \cdots, a_{m}\right)$, o que implica que $x$ é simples, o que completa a demonstração.

\section{Equilibrios Competitivos.}

Nesta seção demonstraremos que os preços de equilíbrio são compatíveis com matchings ótimos e que todo matching ótimo é compatível com qualquer preço de equilíbrio. Se existir mais de um matching ótimo, a Proposição 6 implica que, se $j$ é um comprador que não preencheu a sua cota em algum matching ótimo, então o seu payoff associado a qualquer equilíbrio competitivo será 0 . O Teorema 1 caracteriza os preços de equilíbrio e o Corolário 2 caracteriza os preços mínimo e máximo de equilíbrio.

Lema 1: Seja $(p, x)$ um equilibrio competitivo. Então existe um matching $x^{\prime}$ compativel com $p$, simples para a ordenação $\left(a_{1}, \cdots, a_{m}\right)$, e tal que $\sum_{j} a_{j} x_{j}^{\prime}=\sum_{j} a_{j} x_{j}$.

Demonstração: Seja $x^{\prime}$ definida em $\left({ }^{*}\right)$ a partir de $x$ e de $\left(a_{1}, \cdots, a_{m}\right)$. Então $x^{\prime}$ é simples para $\left(a_{1}, \cdots, a_{m}\right)$ e tem o mesmo valor que $x$. Resta provar que $x^{\prime}$ é compatível com $p$, i.e., que $x_{j}^{\prime} \in D_{j}(p), \forall j \in P$. Então seja $j \in P$. Como $(p, x)$ é um equilíbrio competitivo, sabemos que $x$ é compatível com $p$ e então $x_{k} \in D_{k}(p) \forall k \in P$. Assim, pela construção de $x^{\prime}$, basta mostrar que $x_{j}^{\prime} \in D_{j}(p)$ para o caso em que $a_{j}=a_{k}$ para algum $k$. Seja $\gamma=\left\{k \in P ; a_{k}=a_{j}\right\}$. É claro que $x_{j}^{\prime} \in D_{j}(p)$ no caso em que 
$0<x_{j}<r_{j}$, pois então $D_{j}(p)=\left\{0,1, \cdots, r_{j}\right\}$. Se $x_{j}=0$ então $D_{j}(p)=\{0\}$ ou $D_{j}(p)=\left\{0,1, \cdots, r_{j}\right\}$. Se $D_{j}(p)=\{0\}$ então $a_{j}<p$. Neste caso, $a_{k}<p \forall k \in \gamma$, e portanto $D_{k}(p)=\{0\}$. Logo a compatibilidade entre $x$ e $p$ implica que $x_{k}=0, \forall k \in \gamma$. Da construção de $x^{\prime}$ segue que $\sum_{k \in \gamma} x_{k}^{\prime}=\sum_{k \in \gamma} x_{k}=0$, donde $x_{j}^{\prime}=0$ e portanto $x_{j}^{\prime} \in D_{j}(p)$. Se $D_{j}(p)=\left\{0,1, \cdots, r_{j}\right\}$, é óbvio que $x_{j}^{\prime} \in D_{j}(p)$, pois $0 \leq x_{j}^{\prime} \leq r_{j}$. Se $x_{j}=r_{j}$ então $D_{j}(p)=\left\{r_{j}\right\}$ ou $D_{j}(p)=\left\{0,1, \cdots, r_{j}\right\}$. Necessitamos apenas verificar o caso em que $D_{j}(p)=\left\{r_{j}\right\}$ que implica que $a_{j}>p$. Neste caso, $a_{k}>p \forall k \in \gamma$. Portanto $D_{k}(p)=\left\{r_{k}\right\}$, donde $x_{k}=r_{k} \forall k \in \gamma$. Da definição de $x^{\prime}$ implica que $\sum_{k \in \gamma} x_{k}^{\prime}=\sum_{k \in \gamma} x_{k}=\sum_{k \in \gamma} r_{k}$. Mas $x_{k}^{\prime} \leq r_{k} \forall k \in \gamma$. Logo devemos ter que $x_{k}^{\prime}=r_{k} \forall k \in \gamma$. Em particular $x_{j}^{\prime}=r_{j}$. Então $x_{j}^{\prime} \in D_{j}(p)$ e a demonstração está completa.

Proposição 4: Seja $(p, x)$ um equilıbrio competitivo. Então $x$ é um matching ótimo.

Demonstração: Seja $x^{\prime}$ o matching simples cuja existência é garantida pelo Lema 1. Então $\sum_{j} a_{j} x_{j}^{\prime}=\sum_{j} a_{j} x_{j}$. Assim para mostrar que $x$ é ótimo basta provar que $x^{\prime}$ é ótimo, o que faremos provando que $x^{\prime}$ satisfaz (a) e (b) da Proposição 2. Para provar que $x^{\prime}$ satisfaz (a) considere $\left(a_{1}, \cdots, a_{m}\right)$ uma ordenação para a qual $x^{\prime}$ é simples. Tome $j$ e $k$ com $j<k$ e $a_{j} \geq a_{k}$. Temos de mostrar que se $x_{j}^{\prime}<r_{j}$ então $x_{k}^{\prime}=0$. Então considere $x_{j}^{\prime}<r_{j}$. Como $x^{\prime}$ é compatível com $p$ decorre que $x_{j}^{\prime} \in D_{j}(p)$. Assim $a_{j} \leq p$. Logo $a_{k} \leq p$. Analisaremos primeiro o caso em que $a_{k}<p$. Neste caso temos que $D_{k}(p)=\{0\}$ e portanto $x_{k}^{\prime}=0$, como queríamos. No caso em que $a_{k}=p$ temos que $p \geq a_{j} \geq a_{k}=p$, donde $a_{j}=a_{k}=p$. Como $x^{\prime}$ é simples para $\left(a_{1}, \cdots, a_{j}, \cdots, a_{k}, \cdots, a_{m}\right)$ implica que $x_{j}^{\prime}=\min \left\{r_{j}, x_{j}^{\prime}+x_{k}^{\prime}\right\}$. Mas $x_{j}^{\prime}<r_{j}$. Logo $x_{j}^{\prime}=x_{j}^{\prime}+x_{k}^{\prime}$, donde $x_{k}^{\prime}=0$. Desta forma provamos que $x^{\prime}$ satisfaz a Proposição 2(a). Resta provar que $x^{\prime}$ satisfaz (b), isto é, que $\sum x_{j}^{\prime}=\min \left\{n, \sum_{j} r_{j}\right\}$. De fato, como $x^{\prime}$ é factível, implica que $\sum_{j} x_{j}^{\prime} \leq \min \left\{n, \sum_{j} r_{j}\right\}$. Suponhamos por ab-

Revista de Econometria 18 (2) Novembro 1998 
surdo que $\sum_{j} x_{j}^{\prime}<\min \left\{n, \sum_{j} r_{j}\right\}$. Então $\sum_{j} x_{j}^{\prime}<n$, donde existe, pelo menos, um objeto não alocado. Daí, usando que $\left(p, x^{\prime}\right)$ é um equilíbrio, segue que

$$
p=0
$$

Por outro lado $\sum_{j} x_{j}^{\prime}<\sum_{j} r_{j}$, donde existe pelo menos um comprador $j$ que não preencheu a sua cota. Logo

$$
x_{j}^{\prime}<r_{j}
$$

Pela observação $1, a_{j}>0$. Mas então $a_{j}>p$, por (1), o que implica que $D_{j}(p)=\left\{r_{j}\right\}$. Desse modo $x_{j}^{\prime} \notin D_{j}(p)$, por (2), o que contradiz o fato de que $x^{\prime}$ é compatível com $p$.

Portanto, $x^{\prime}$ satisfaz (a) e (b) da Proposição 2, donde segue que $x^{\prime}$ é ótimo, como queríamos demonstrar.

Proposição 5: Seja $x$ um matching ótimo e $p$ um preço competitivo. Então $x$ é compativel com $p$.

Demonstração: Seja $x^{\prime}$ definida em $\left({ }^{*}\right)$ a partir de $x$ e da ordenação $\left(a_{1}, \cdots, a_{m}\right)$. Então $x^{\prime}$ é simples para $\left(a_{1}, \cdots, a_{m}\right)$. Além disso $\sum_{j} a_{j} x_{j}=\sum_{j} a_{j} x_{j}^{\prime}$, o que implica que $x^{\prime}$ é ótimo. Pelo Lema 1 , dada a ordenação $\left(a_{1}, \cdots, a_{m}\right)$, existe um matching $x^{\prime \prime}$ simples para $\left(a_{1}, \cdots, a_{m}\right)$ que é compatível com $p$. Este matching é ótimo, pela Proposição 3. Como existe somente um matching ótimo e simples para uma dada ordenação, temos que $x^{\prime}=x^{\prime \prime}$, logo $x^{\prime}$ é compatível com $p$. Quero mostrar que $x_{j} \in D_{j}(p), \forall j \in P$. Então seja $j \in P$. É suficiente provar para o caso em que $a_{j}=a_{k}$ para algum $k$, desde que caso contrário $x_{j}=x_{j}^{\prime}$ e $x_{j}^{\prime} \in D_{j}(p)$. Então seja $\gamma=\left\{k \in P ; a_{k}=a_{j}\right\}$. É claro que $x_{j} \in D_{j}(p)$ no caso em que $0<x_{j}^{\prime}<r_{j}$, pois então $D_{j}(p)=\left\{0,1, \cdots, r_{j}\right\}$. Se $x_{j}^{\prime}=0$ então $D_{j}(p)=\{0\}$ ou $D_{j}(p)=\left\{0,1, \cdots, r_{j}\right\}$. Basta considerar o caso em que $D_{j}(p)=\{0\}$, visto que o outro é obviamente verificado. Neste 
caso $a_{j}<p$ e portanto, $a_{k}<p \forall k \in \gamma$, donde $D_{k}(p)=\{0\}$ e então $x_{k}^{\prime}=0$. Da construção de $x^{\prime}$ segue que $0=\sum_{k \in \in^{\prime} \gamma} x_{k}^{\prime}=\sum_{k \in \in_{\gamma}} x_{k}$, donde $x_{k}=0 \forall k \in \gamma$. Em particular, $x_{j}=0$ e portanto $x_{j} \in D_{j}(p)$.

Se $x_{j}^{\prime}=r_{j}$ então $D_{j}(p)=\left\{r_{j}\right\}$ ou $D_{j}(p)=\left\{0,1, \cdots, r_{j}\right\}$. Se $D_{j}(p)=\left\{r_{j}\right\}$ então $a_{j}>p$, o que implica que $a_{k}>p . \forall k \in \gamma$. Portanto $D_{k}(p)=\left\{r_{k}\right\}$, donde $x_{k}^{\prime}=r_{k} \forall k \in \gamma$. Da construção de $x^{\prime}$ temos que $\sum_{k \in \gamma} r_{k}=\sum_{k \in \gamma} x_{k}^{\prime}=\sum_{k \in \gamma} x_{k}$. Mas $x_{k} \leq r_{k} \forall k \in \gamma$. Logo devemos ter que $x_{k}=r_{k} \forall k \in \gamma$. Em particular $x_{j}=r_{j}$ e então $x_{j} \in D_{j}(p)$. Portanto, $x_{j} \in D_{j}(p) \forall j \in P$ e a demonstração está completa.

Seja $x$ um matching ótimo e simples. Defina:

$$
\begin{array}{ll}
A_{x}=\{j \in P ; & \left.x_{j}=r_{j}\right\}, \\
B_{x}=\{j \in P ; & \left.0<x_{j}<r_{j}\right\} \mathrm{e} \\
C_{x}=\{j \in P ; & \left.x_{j}=0\right\} .
\end{array}
$$

Observação 4: Seja $x$ um matching ótimo e simples para a ordenação $\left(a_{1}, \cdots, a_{m}\right)$. Da observação 3 segue que se $B_{x} \neq \emptyset$, então $B_{x}=\{j\}$, para algum $j$. Mais ainda, $a_{k} \geq a_{j} \geq a_{k^{\prime}}, \forall k \in A_{x} \mathrm{e}$ $\forall k^{\prime} \in C_{x}$. Se $B_{x}=\emptyset$ então $a_{k} \geq a_{k^{\prime}}, \forall k \in A_{x}$ e $\forall k^{\prime} \in C_{x}$.

Definição 8: $p^{*}$ é o preço máximo de equilibrio se $p^{*} \geq p$ para todo preço de equilibrio $p$; $p^{*}$ é o preço minimo de equilibrio se $p^{*} \leq p$ para todo preço de equilibrio $p$.

Definição 9: Seja $(p, x)$ um equilibrio competitivo. O vetor de payoffs associado a $(p, x)$ é o vetor $u=\left(u_{1}, \cdots, u_{m}\right)$ onde $u_{j}=$ $\max \left\{0, a_{j}-p\right\}, \forall j \in P$. $O$ payoff total de $j \in P$ associado $a$ $(p, x)$ é dado por $x_{j} u_{j}$.

Se $(p, x)$ é um equilíbrio competitivo e $u$ é o vetor de payoffs associado a $(p, x)$, então a Definição 9 implica que $u_{j} \geq 0$ e $u_{j} \geq$

Revista de Econometria 18 (2) Novembro 1998 
$a_{j}-p \forall j \in P$. Como $(p, x)$ é um preço competitivo decorre também que se $x$ designa algum objeto para $j$, i.e. $x_{j} \neq 0$, então $D_{j}(p) \neq\{0\}$, donde $a_{j}-p \geq 0$ e portanto $u_{j}=a_{j}-p$. Se nenhum objeto é alocado por $x$ para $j$ então $x_{j}=0$ e $D_{j}(p)=\left\{0, \cdots, r_{j}\right\}$ ou $D_{j}(p)=\{0\}$, donde $a_{j}-p \leq 0$. Neste caso $u_{j}=0$, i.e.:

$$
\begin{array}{ll}
u_{j} \geq 0 \quad \text { e } & u_{j} \geq a_{j}-p \forall j \in P \\
u_{j}=a_{j}-p & \text { se } \quad x_{j}>0 \text { e } \\
u_{j}=0 \quad \text { se } & x_{j}=0 .
\end{array}
$$

Observe também que se $u_{j}>0$ então $x_{j}>0$, donde $u_{j}=a_{j}-$ $p>0$ e portanto $D_{j}(p)=\left\{r_{j}\right\}$. Como $(p, x)$ é competitivo segue que $x_{j}=r_{j}$. Temos também que, se $x^{\prime}$ é ótimo, então $\left(p, x^{\prime}\right)$ é competitivo, donde $x_{j}^{\prime} \in D_{j}(p)=\left\{r_{j}\right\}$. Logo $x_{j}^{\prime}=r_{j}$ para todo matching ótimo. Temos assim demonstrado o seguinte resultado.

Proposição 6: Seja $(p, x)$ um equilibrio competitivo. Seja u o vetor de payoffs associado $a(p, x)$. Seja $j \in P$. Se $u_{j}>0$ então $j$ completa sua cota em todo matching ótimo. Neste caso o payoff total de $j$ é $r_{j} u_{j}$.

Se $u_{j}=0$ então o payoff total de $j$ é 0 . Em qualquer caso, portanto, o payoff total de $j$ é $r_{j} u_{j}$.

Teorema 1: Seja $x$ um matching ótimo e simples. (a) $S e B_{x}=\{j\}$ então existe um único preço de equilíbrio dado por $p=a_{j}$; (b) se $B_{x}=\emptyset$, seja $a_{t}=\min \left\{a_{k} ; k \in A_{x}\right\}$ e $a_{t^{\prime}}=\max \left\{a_{k} ; k \in C_{x}\right\}$ se $C_{x} \neq \emptyset$. Então o conjunto dos preços de equilibrio é dado por

i) $\left[a_{t}^{\prime}, a_{t}\right]$ se $C_{x} \neq \emptyset$;

ii) $\left[0, a_{t}\right]$ se $C_{x}=\emptyset$ e $n=\sum_{j} r_{j}$ e

iii) $\{0\}$ se $C_{x}=\emptyset$ e $n>\sum_{j} r_{j}$. 
Demonstração: (a) Para ver que $p=a_{j}$ é competitivo é suficiente mostrar que $x_{k} \in D_{k}(p)$ para todo $k \in P$. Então, se $k \in A_{x}, a_{k} \geq p$ pela observação 4. Se $a_{k}>p$ temos que $D_{k}(p)=\left\{r_{k}\right\}$ e se $a_{k}=p$ implica que $D_{k}(p)=\left\{0,1, \cdots, r_{k}\right\}$. Em ambos os casos $x_{k} \in D_{k}(p)$, visto que $x_{k}=r_{k}$ pela definição de $A_{x}$. Se $k \in C_{x}$ então $a_{k} \leq a_{j}=p$, pela observação 4 . Se $a_{k}<p$ temos que $D_{k}(p)=\{0\}$ e se $a_{k}=p$ implica que $D_{k}(p)=\left\{0,1, \cdots, r_{k}\right\}$. Em ambos os casos $x_{k} \in D_{k}(p)$, visto que $x_{k}=0$ pela definição de $C_{x}$. Quanto a $j$, como $p=a_{j}$, temos que $D_{j}(p)=\left\{0, \cdots, r_{j}\right\}$. Como $0<x_{j}<r_{j}$, por definição de $B_{x}$, segue que $x_{j} \in D_{j}(p)$. Portanto $x_{k} \in D_{k}(p)$ para todo $k \in P$. Além disso, a Proposição 1 implica que se $0<x_{j}<r_{j}$ então não existem objetos não vendidos. Portanto $p=a_{j}$ é um preço de equilíbrio e $\left(a_{j}, x\right)$ é um equilíbrio competitivo.

Para ver que $p=a_{j}$ é o único preço de equilíbrio, basta observar que, como $x$ é ótimo, então $x$ é compatível com $p^{\prime}$, para qualquer preço de equilíbrio $p^{\prime}$, pela Proposição 4 . Então se $a_{j}>p^{\prime}$ deveremos ter que $x_{j}=r_{j}$ e se $a_{j}<p^{\prime}$ deveremos ter que $x_{j}=0$. Qualquer dos dois casos é um absurdo, visto que $0<x_{j}<r_{j}$. Logo, $p^{\prime}=a_{j}$, o que completa a demonstração da parte (a).

Para provar a parte (b) suponhamos que $p$ é um preço de equilíbrio e $B_{x}=\emptyset$. Então, $(p, x)$ é um equilíbrio competitivo e portanto $x_{k} \in D_{k}(p) \forall k \in P$. Em particular $x_{t} \in D_{t}(p)$ e $x_{t^{\prime}} \in D_{t}(p)$ no caso em que $t^{\prime}$ exista. Como $t \in A_{x}$ segue que $x_{t}=r_{t}$ e então $r_{t} \in D_{t}(p)$, donde $D_{t}(p)=\left\{r_{t}\right\}$ ou $D_{t}(p)=\left\{0,1, \cdots, r_{t}\right\}$, donde

$$
p \leq a_{t} .
$$

Se $t^{\prime}$ existir, isto é, se $C_{x} \neq \emptyset$, então, como $t^{\prime} \in C_{x}$ segue que $x_{t^{\prime}}=0$ donde $0 \in D_{t^{\prime}}(p)$, donde $D_{t^{\prime}}(p)=\{0\}$ ou $D_{t^{\prime}}(p)=\left\{0, \cdots, r_{t^{\prime}}\right\}$, donde $p \geq a_{t^{\prime}}$. Logo, $p \in\left[a_{t^{\prime}}, a_{t}\right]$. Na outra direção tome $p \in\left[a_{t^{\prime}}, a_{t}\right]$. Temos que $a_{k} \geq a_{t} \geq p \forall k \in A_{x}$. Então, $\forall k \in A_{x}, a_{k} \geq p$, donde $D_{k}(p)=\left\{r_{k}\right\}$ ou $D_{k}(p)=\left\{0, \cdots, r_{k}\right\}$. Assim $r_{k} \in D_{k}(p) \forall k \in A_{x}$. 
Pela definição de $A_{x}$ implica que $x_{k} \in D_{k}(p) \forall k \in A_{x}$. Resta provar que $x_{k} \in D_{k}(p) \forall k \in C_{x}$. Observe que $\forall k \in C_{x}, p \geq a_{t^{\prime}} \geq a_{k}$, donde $p \geq a_{k}$, donde $D_{k}(p)=\{0\}$ ou $D_{k}(p)=\left\{0, \cdots, r_{k}\right\}$. Assim $0 \in D_{k}(p) \forall k \in C_{x}$. Agora use a definição de $C_{x}$ para ver que $x_{k} \in D_{k}(p) \forall k \in C_{x}$. Portanto, $x_{k} \in D_{k}(p) \forall k \in P$, o que mostra que $p$ é competitivo. Como $C_{x} \neq \emptyset$ implica que não existem objetos não vendidos. Portanto, $p$ é um preço de equilíbrio e temos provado (i).

Se $C_{x}=\emptyset$ então $P=A_{x}$. Seja $p$ um preço de equilíbrio. Por (1) obtemos que $0 \leq p \leq a_{t}$. Agora vamos provar que se $p \in\left[0, a_{t}\right]$ então $p$ é um preço competitivo. De fato, seja $0 \leq p \leq a_{t}$. Temos que $a_{k} \geq a_{t} \geq p \forall k \in A_{x}=P$. Então $\forall k \in P, a_{k} \geq p$, donde $D_{k}(p)=$ $\left\{r_{k}\right\}$ ou $D_{k}(p)=\left\{0, \cdots, r_{k}\right\}$, donde $r_{k} \in D_{k}(p)$. A definição de $A_{x}$ implica que $x_{k} \in D_{k}(p) \forall k \in P$, o que mostra que $p$ é competitivo. Portanto, $\left[0, a_{t}\right]$ é o conjunto dos preços competitivos. Para provar (ii) considere $n=\sum_{j} r_{j}$. Então não existem objetos não vendidos e portanto todo preço competitivo é de equilíbrio. Para provar (iii) considere $n>\sum_{j} r_{j}$. Neste caso existem objetos não vendidos. $\grave{A}$ luz da Definição 3 , o único preço competitivo em $\left[0, a_{t}\right]$ que é de equilíbrio é $p=0$, como queríamos demonstrar.

Corolário 2: Seja $x$ um matching ótimo e simples. Então

i) $p^{*}=p *=a_{j} \quad$ se $\quad B_{x}=\{j\}$;

ii) $p^{*}=\min \left\{a_{j} ; j \in A_{x}\right\}$ e $p_{*}=\max \left\{a_{j} ; j \in\right.$ $\left.C_{x}\right\}, \quad$ se $\quad B_{x}=\emptyset$ e $C_{x} \neq \emptyset$

iii) $p^{*}=\min \left\{a_{j} ; j \in A_{x}\right\} \quad$ e $\quad p_{*}=0 \quad$ se $\quad B_{x}=\emptyset, \quad C_{x}=$ $\emptyset \mathrm{e} \quad n=\sum_{j} r_{j} \mathrm{e}$

iv) $p^{*}=p_{*}=0 \quad$ se $\quad B_{x}=\emptyset, C_{x}=\emptyset \quad$ e $\quad n>\sum_{j} r_{j}$.

Demonstração: Imediata a partir do Teorema 1. 


\section{Marilda Sotomayor}

\section{Estática Comparativa.}

Esta sessão enuncia e demonstra os resultados de estática comparativa que respondem à pergunta: $O$ que acontece com os preços ótimos de equilibrio quando novos compradores ou mais objetos entram no mercado?

Necessitamos de algumas definições e resultados preliminares.

Lema 2: Sejam a e e $a^{\prime \prime} \in R_{+}^{n}$ com $a^{\prime} \geq a^{\prime \prime}$. Sejam $\left(p^{\prime}, x^{\prime}\right)$ e $\left(p^{\prime \prime}, x^{\prime}\right)$ equilibrios competitivos para $M^{\prime}=\left(P, Q, r, a^{\prime}\right)$ e $M^{\prime \prime}=\left(P, Q, r, a^{\prime \prime}\right)$, respectivamente. Sejam $u^{\prime}$ e $u^{\prime \prime}$ os vetores de payoffs associados a $\left(p^{\prime}, x^{\prime}\right)$ e $\left(p^{\prime \prime}, x^{\prime \prime}\right)$, respectivamente. Defina $P^{1}=\left\{j \in P ; u_{j}^{\prime}>u_{j}^{\prime \prime}\right\}$, $P^{2}=\left\{j \in P ; u_{j}^{\prime \prime}>u_{j}^{\prime}\right\}$ e $P^{0}=\left\{j \in P ; u_{j}^{\prime}=u_{j}^{\prime}\right\}$. Se $p^{\prime}<p^{\prime \prime}$ então $P^{2}=\emptyset$, todos os objetos são designados a compradores de $P^{1}$ por ambos os matchings e todo comprador $j \in P^{1}$ preenche a sua cota em ambas as alocaçōes. Consequentemente $x^{\prime}=x^{\prime \prime}$ e $u_{j}^{\prime}=u_{j}^{\prime \prime}=$ $0 \forall j \in P^{0}$.

Demonstração: Se $j \in P^{1}$ então $u_{j}^{\prime}>u_{j}^{\prime \prime} \geq 0$ e, portanto, $j$ preenche a sua cota em $x^{\prime}$ pela Proposição 5. Então

$$
\sum r_{j} \leq n, \text { com } j \in P^{1} .
$$

Como $p^{\prime \prime}>p^{\prime} \geq 0$, então todos os objetos são designados por $x^{\prime \prime}$. Então, dado um comprador $j$, se algum objeto é alocado a $j$ por $x^{\prime \prime}$, implica que $j \in P^{1}$, pois caso contrário $a_{j}^{\prime \prime}=u_{j}^{\prime \prime}+p^{\prime \prime}>u_{j}^{\prime}+p^{\prime} \geq a_{j}^{\prime}$, onde na última desigualdade usamos (5.1). Mas então $a_{j}^{\prime \prime}>a_{j}^{\prime}$, contradição. Portanto, todos os objetos são designados a compradores de $P^{1}$ por $x^{\prime \prime}$. Assim

$$
\sum r_{j} \geq n, \text { para } j \in P^{1} .
$$

Por (1) e (2) temos que $\sum r_{j}=n$, para $j \in P^{1}$. Desta forma, como todo comprador de $P^{1}$ preenche a sua cota com $x^{\prime}$, temos que todos

Revista de Econometria 18 (2) Novembro 1998 
os objetos são designados aos compradores de $P^{1}$ por $x^{\prime}$. Mostramos então que em ambas as alocaçōes, todos os objetos são designados a $P^{1}$ e todos os compradores de $P^{1}$ preenchem sua cota. Para mostrar que $P^{2}=\emptyset$, suponha por contradição que não. Seja $j \in P^{2}$. Então $u_{j}^{\prime \prime}>u_{j}^{\prime} \geq 0$, o que implica que $j$ completa sua cota em $x^{\prime \prime}$, pela Proposição 5. Logo algum objeto é designado a $j$ por $x^{\prime \prime}$. Mas todo objeto é alocado a $P^{1}$ por $x^{\prime \prime}$, o que é um absurdo. Logo $P^{2}=\emptyset$. Se $j \in P^{0}, x^{\prime}$ e $x^{\prime \prime}$ não designam nenhum objeto a $j$. Isto implica que $u_{j}^{\prime}=u_{j}^{\prime \prime}=0$. É evidente então que $x^{\prime}=x^{\prime \prime}$ e a demonstração está completa.

Lema 3: Sejam $M^{\prime}=\left(P, Q^{\prime}, r, a\right)$ e $M^{\prime \prime}=\left(P, Q^{\prime \prime}, r, a\right)$. Sejam $n^{\prime}=$ $\left|Q^{\prime}\right|$ e $n^{\prime \prime}=\left|Q^{\prime \prime}\right|$. Sejam $\left(p^{\prime}, x^{\prime}\right)$ e $\left(p^{\prime \prime}, x^{\prime \prime}\right)$ equilibrios competitivos para $M^{\prime}$ e $M^{\prime \prime}$, respectivamente. Se $n^{\prime \prime}>n^{\prime}$ então $p^{\prime} \geq p^{\prime \prime}$.

Demonstração: Sejam $u^{\prime}$ e $u^{\prime \prime}$ os vetores de payoffs associados a $\left(p^{\prime}, x^{\prime}\right)$ e $\left(p^{\prime \prime}, x^{\prime \prime}\right)$, respectivamente. Suponha por contradição que $0 \leq p^{\prime}<p^{\prime \prime}$. Então todo objeto é alocado por $x^{\prime \prime}$. Defina $P^{1}$ como no Lema 2. Se algum objeto é alocado por $x^{\prime \prime}$ para algum comprador $j$, então $j \in P^{1}$. De fato, se $u_{j}^{\prime} \leq u_{j}^{\prime \prime}$ temos que, usando também (5.1), $a_{j}=u_{j}^{\prime \prime}+p^{\prime \prime}>u_{j}^{\prime}+p^{\prime} \geq a_{j}$. Mas então $a_{j}>a_{j}$, absurdo. Logo todo objeto é alocado para $P^{1}$ por $x^{\prime \prime}$ e

$$
\sum r_{j} \geq n^{\prime \prime}, \text { para } j \in P^{1}
$$

Por outro lado, todo comprador $j \in P^{1}$ preenche a sua cota com $x^{\prime}$, desde que $u_{j}^{\prime}>u_{j}^{\prime \prime} \geq 0$. Portanto

$$
\sum r_{j} \leq n^{\prime}, \text { para } j \in P^{1}
$$

Por (1) e (2) temos que $n^{\prime \prime} \leq n^{\prime}$, contradição. Logo $p^{\prime} \geq p^{\prime \prime}$.

Lema 4: Sejam $a^{\prime}$ e $a^{\prime \prime} \in R_{+}^{n} \operatorname{com} a^{\prime} \geq a^{\prime \prime}$. Sejam $\left(p^{\prime}, x^{\prime}\right)$ e $\left(p^{\prime \prime}, x^{\prime}\right)$ equilibrios competitivos para $M^{\prime}=\left(P, Q, r, a^{\prime}\right)$ e $M^{\prime \prime}=\left(P, Q, r, a^{\prime \prime}\right)$, 
respectivamente. Entäo, (a) $\lambda_{*}=\min \left\{p^{\prime}, p^{\prime \prime}\right\}$ é competitivo para $M^{\prime \prime}$ e (b) $\lambda^{*}=\max \left\{p^{\prime}, p^{\prime \prime}\right\}$ é competitivo para $M^{\prime}$.

Demonstração: Se $a^{\prime}=a^{\prime \prime}$ o resultado é óbvio. Consideremos então que $a^{\prime}>a^{\prime \prime}$. Se $p^{\prime \prime} \leq p^{\prime}$, nada temos a mostrar. Se $p^{\prime}<p^{\prime \prime}$, então pelo Lema 2 , todos os objetos são designados para $P^{1}$, todos os compradores de $P^{1}$ preenchem a sua cota em ambos os matchings e $x^{\prime}=x^{\prime \prime}$. Assim sendo, $\forall j \in P^{1}, a_{j}^{\prime \prime}-p^{\prime \prime} \geq 0$. Então

$$
\begin{aligned}
& a_{j}^{\prime \prime}-p^{\prime}>a_{j}^{\prime \prime}-p^{\prime \prime} \geq 0, \quad \forall j \in P^{1} \\
& a_{j}^{\prime}-p^{\prime \prime} \geq a_{j}^{\prime \prime}-p^{\prime \prime} \geq 0 \quad \forall j \in P^{1}
\end{aligned}
$$

(1) implica que $a_{j}^{\prime \prime}-p^{\prime}>0$. (2) implica que $a_{j}^{\prime}-p^{\prime \prime} \geq 0$. Portanto, $j \in$ $P^{1}, r_{j}$ é uma quantidade demandada por $j$ ao preço $p^{\prime}$ no mercado $M^{\prime \prime}$ e ao preço $p^{\prime \prime}$ no mercado $M^{\prime}$. Se $j \notin P^{1}$ então, pelo Lema 2, $j \in P^{0}$. Neste caso $j$ não recebe nenhum objeto por $x^{\prime}$, o que implica que $a_{j}^{\prime}-p^{\prime} \leq 0$. Então

$$
\begin{aligned}
& a_{j}^{\prime \prime}-p^{\prime} \leq a_{j}^{\prime}-p^{\prime} \leq 0 \\
& a_{j}^{\prime}-p^{\prime \prime}<a_{j}^{\prime}-p^{\prime} \leq 0
\end{aligned}
$$

Logo $a_{j}^{\prime \prime}-p^{\prime} \leq 0$ e $a_{j}^{\prime}-p^{\prime \prime}<0$. Por conseguinte, 0 é uma quantidade demandada por $j$ ao preço $p^{\prime}$ no mercado $M^{\prime \prime}$ e ao preço $p^{\prime \prime}$ no mercado $M^{\prime}$. Em qualquer caso temos que a quantidade de objetos que cada comprador $j \in P$ está recebendo ao preço $p^{\prime}$ no mercado $M^{\prime \prime}$, é uma quantidade demandada por $j$ ao preço $p^{\prime}$ no mercado $M^{\prime \prime}$. Da mesma forma, a quantidade de objetos que cada comprador $j \in P$ está recebendo ao preço $p^{\prime \prime}$ no mercado $M^{\prime}$, é uma quantidade demandada por $j$ ao preço $p^{\prime \prime}$ no mercado $M^{\prime}$. Assim $p^{\prime}$ é competitivo para $M^{\prime \prime}$ e $p^{\prime \prime}$ é competitivo para $M^{\prime}$. Como não existem objetos não designados, $\left(p^{\prime}, x^{\prime}\right)$ é um equilíbrio competitivo para $M^{\prime \prime}$ e $\left(p^{\prime \prime}, x^{\prime \prime}\right)$ é um equilíbrio competitivo para $M^{\prime}$, como queríamos demonstrar. 
Lema 5: Sejam a $a^{\prime}$ e $a^{\prime \prime} \in R_{+}^{n}$. Sejam $p_{*}^{\prime}, p^{\prime *}, p_{*}^{\prime \prime}$ e $p^{\prime \prime *}$ os preços mínimo e máximo de equilibrio para $M^{\prime}=\left(P, Q, r, a^{\prime}\right)$ e $M^{\prime \prime}=\left(P, Q, r, a^{\prime \prime}\right)$, respectivamente. Se $a \geq a^{\prime \prime}$ então $p_{*}^{\prime} \geq p_{*}^{\prime \prime} e$ $p^{\prime *} \geq p^{\prime *}$.

Demonstração: Pelo Lema $4, \lambda_{*}=\min \left\{p_{*}^{\prime}, p_{*}^{\prime \prime}\right\}$ é competitivo para $M^{\prime \prime}$ e $\lambda^{*}=\max \left\{p^{\prime *}, p^{\prime \prime *}\right\}$ é competitivo para $M^{\prime}$. Logo, $p_{*}^{\prime \prime} \leq \lambda_{*} \leq p_{*}^{\prime}$ pela minimalidade de $p_{*}^{\prime \prime}$ em $M^{\prime \prime}$ e $p^{\prime *} \geq \lambda^{*} \geq p^{\prime \prime *}$ pela maximalidade de $p^{* *}$ em $M^{\prime}$. O resultado desejado então segue.

Teorema 2: (a) Se um conjunto de compradores adicionais entra no mercado, então $p^{*}$ e $p_{*}$ não decrescem. (b) Se um conjunto de objetos adicionais entra no mercado, então $p^{*}$ e $p_{*}$ não crescem.

Demonstração: Para provar (a) considere o mercado $M^{\prime}=$ $\left(P^{\prime}, Q, r^{\prime}, a^{\prime}\right)$ onde $P \subseteq P^{\prime}, r_{j}^{\prime}=r_{j}$ e $a_{j}^{\prime}=a_{j}$ para todo $j \in P$. Seja $p_{*}^{\prime}$ e $p^{\prime *}$ os preços de equilíbrio mínimo e máximo, respectivamente, para $M^{\prime}$. Mostraremos que $p_{*}^{\prime} \geq p_{*}$ e $p^{\prime *} \geq p^{*}$. De fato, defina $a^{\prime \prime}$ tal que $a_{j}^{\prime \prime}=a_{j}^{\prime}$ se $j \in P$ e $a_{j}^{\prime \prime}=0$ para todo $j \in P^{\prime}-P$. Sejam $p_{*}^{\prime \prime}$ e $p^{\prime \prime *}$ os preços mínimo e máximo de equilíbrio para $M^{\prime \prime}$. É claro que a passagem do mercado $M$ para $M^{\prime \prime}$ não altera o conjunto dos preços de equilíbrio, desde que todos os novos compradores têm avaliação 0. Portanto, $p_{*}^{\prime \prime}=p_{*}$ e $p^{\prime \prime *}=p^{*}$. Agora observe que $a^{\prime} \geq a^{\prime \prime}$. Então podemos aplicar o Lema 5 e obter que $p_{*}^{\prime} \geq p_{*}^{\prime \prime}=p_{*}$ e $p^{\prime *} \geq p^{\prime \prime *}=p^{*}$. Logo, $p_{*}^{\prime} \geq p_{*}$ e $p^{\prime *} \geq p^{*}$.

Para provar (b) considere $M^{\prime}$ um mercado que difere de $M$ somente na quantidade de objetos dos conjuntos $Q^{\prime}$ e $Q$, respectivamente. Seja $n^{\prime}=\left|Q^{\prime}\right|>n=|Q|$. Sejam $\left(p_{*}^{\prime}, x^{\prime}\right)$ e $\left(p^{\prime *}, x^{\prime}\right)$ equilíbrios competitivos para $M^{\prime}$. Agora use o Lema 3 e obtenha que $p^{*} \geq p^{\prime *}$ e $p_{*} \geq p_{*}^{\prime}$. 


\section{O Mecanismo de Leilão Dinâmico.}

Nesta seção reformulamos o mecanismo de leilão dinâmico, de objetos idênticos, com preços ascendentes, amplamente citado na literatura. Suporemos que todos os preços e avaliações são números inteiros não negativos. A unidade de preço poderia ser, digamos, um dólar ou cem dólares, dependendo do tipo de ítem a ser leiloado. Este mecanismo, que será chamado aqui simplesmente de leilão dinâmico, computa o preço mínimo de equilíbrio num número finito de etapas.

Para descrevermos o mecanismo faremos uso das seguintes definições e notações:

- O conjunto das demandas de $j$ ao preço $p(t)$ será denotado por $D_{j}(t)$.

- O conjunto das demandas totais ao preço $p(t)$ é definido por: $T(t)=\left\{z\right.$ inteiro; $\left.z=x_{1}+\cdots+x_{m} \operatorname{com} x_{j} \in D_{j}(t) \forall j \in P\right\}$.

- A demanda total máxima ao preço $p(t)$ é

$$
d^{*}(t) \equiv \max T(t)
$$

- A demanda total mínima ao preço $p(t)$ é

$$
d_{*}(t) \equiv \min T(t) .
$$

Verifica-se facilmente que se $d^{*}(t)=d_{*}(t)+k$, para algum inteiro $k \geq 0$, então $T(t)=\left\{d_{*}(t), d_{*}(t)+1, \cdots, d_{*}(t)+k=d^{*}(t)\right\}$.

É claro também que se $x$ é um matching compatível com $p(t)$ então $x_{j} \in D_{j}(t) \forall j \in P$ e, portanto, $\sum_{j} x_{j} \in T(t)$. 
Observação 4: Se $n<d_{*}(t)$ então não existe um matching compatível com $p(t)$. De fato, se $x$ fosse um tal matching deveríamos ter que $x$ é factível e, portanto, $\sum_{j} x_{j} \leq n$, donde $\sum_{j} x_{j}<d_{*}(t)$, donde $\sum_{j} x_{j} \notin T(t)$, o que contradiz a hipótese de que $x$ é compatível com $p(t)$.

\section{Descrição do mecanismo}

Começamos com um preço inicial anunciado pelo leiloeiro e igual ao preço de reserva do vendedor: $p(0)=0 .{ }^{2}$ Cada comprador "submete um lance" anunciando que quantidades de ítens estaria interessado em comprar ao preço inicial. Isto poderia ser feito do seguinte modo. O leiloeiro perguntaria que compradores estariam interessados em comprar 0 ítem, 1 ítem, 2 ítens, etc, ao preço $p(0)$. Isto é, o comprador informa qual o seu conjunto de demanda ao preço $p(0)$.

Etapa t: Cada comprador informa qual o seu conjunto de demanda ao preço $p(t)$. Depois que os lances são anunciados, o leiloeiro deter$\operatorname{mina} T(t), d^{*}(t)$ e $d_{*}(t)$.

\section{0 caso: $n \geq d^{*}(t)$}

Então existe algum matching $x(t)$ (pode existir mais de um) com $\max \left\{0, n-d^{*}(t)\right\}$ objetos não designados, $\min \left\{n, d^{*}(t)\right\}=x_{1}(t)+$ $\cdots+x_{m}(t)$ e $x_{j}(t) \in D_{j}(t) \forall j \in P$, e tal que existe, no máximo, um comprador $j$ com $0<x_{j}(t)<r_{j}$. Neste caso o leilão termina. Se existir mais de um matching como $x(t)$ o leiloeiro usa alguma regra de desempate de conhecimento comum. (Os desempates poderiam ser feitos, por exemplo, usando-se uma ordenação dos nomes dos compradores em ordem alfabética). O preço final é $p(t)$.

\footnotetext{
${ }^{2} \mathrm{O}$ mecanismo e os resultados apresentados aqui nāo se alteram se o preço de reserva anunciado pelo leiloeiro for $p(0)$ diferente de 0 . $\dot{E}$ claro, que neste caso, devemos substituir os $a_{j}$ 's por $a_{j}-p(0)$.
} 


\section{$2^{\circ}$ caso: $n<d^{*}(t)$}

Neste caso não existe um matching compatível com $p(t)$, pela observação 4. Então o leiloeiro aumenta o preço dos ítens em uma unidade. Isto define $p(t+1)=p(t)+1$. Em seguida cada comprador informa o seu conjunto de demanda ao preço $p(t+1)$. Se não existir um matching compatível com $p(t+1)$ o leiloeiro aumenta o preço dos objetos em uma unidade. É claro que este procedimento não pode ocorrer indefinidamente, porque tão logo o preço se torne mais alto do que qualquer avaliação, ninguém demandará uma quantidade positiva.

É óbvio, da construção do mecanismo, que o preço final obtido, $p$, é um preço competitivo e o matching $x$, correspondente, é compativel com $p$, e por conseguinte é ótimo. Além disso existe, no máximo, um comprador $j$ com $0<x_{j}<r_{j}$. Decorre então da Proposição 6 que $x$ é simples. Na verdade, como será mostrado no Teorema $3, p$ é o preço mínimo de equilíbrio.

Observação 5: Cumpre observar que a fim de que o mecanismo de leilão dinâmico funcione e produza o preço mínimo de equilíbrio, é necessário que os compradores sejam bastante precisos em suas respostas às mudanças de preços. Especificamente, requeremos que cada comprador demande todas as quantidades de ítens que maximizem o seu excedente ao preço corrente, em cada etapa do leilão. Além disso se, por exemplo, um comprador demandar $k$ ítens em alguma etapa $t$, i.e., se o seu conjunto de demanda ao preço $p(t)$ é $\{k\}$, na etapa $t+1$ ele deverá manter sua demanda ou demandar $\{0,1, \cdots, k\}$; se ele demandar $\{0,1, \cdots, k\}$ em alguma etapa $t$ então na etapa $t+1$ ele deverá demandar $\{0\}$; se ele demandar $\{0\}$ em alguma etapa $t$ então ele continuará a demandar $\{0\}$ nas etapas seguintes, até o final do leilão. Isto é uma consequência do requerimento de que sua avaliação é um número inteiro de unidades e os preços aumentam uma unidade em cada etapa. Não é difícil ver

Revista de Econometria 18 (2) Novembro 1998 
então que $\forall t \geq 1$ :

$$
\begin{aligned}
& d^{*}(t)=d_{*}(t-1), \\
& T(t)=\left\{d_{*}(t), d_{*}(t)+1, \cdots, d^{*}(t)=d_{*}(t-1)\right\}, \\
& d^{*}(0) \geq d^{*}(1) \geq \cdots \geq 0 \text { e } \quad d_{*}(0) \geq d_{*}(1) \geq \cdots \geq 0 .
\end{aligned}
$$

Decorre então que $\left\{0,1,2, \cdots, d^{*}(0)\right\}=\bigcup_{t \geq 0} T(t)$.

O seguinte exemplo ilustra nosso mecanismo.

Exemplo 2: Considere o mercado onde $Q$ tem 5 objetos, $P=$ $\left\{p_{1}, \cdots, p_{5}\right\}, r_{1}=1, r_{2}=r_{3}=2, r_{4}=1, r_{5}=2, a_{1}=8, a_{2}=7$, $a_{3}=6, a_{4}=6$ e $a_{5}=3$. Suponha que o preço de reserva dos objetos para o vendedor é 0 . O leiloeiro inicia o leilão anunciando $p(0)=0$. Os compradores indicam seus conjuntos de demanda:

$$
\begin{array}{ll}
D_{1}(0)=\{1\}, & D_{2}(0)=D_{3}(0)=\{2\}, \\
D_{4}(0)=\{1\} \quad \text { e } \quad D_{5}(0)=\{2\} .
\end{array}
$$

O leiloeiro verifica que $n=5<d_{*}(0)=8$. Então aumenta o preço para $p(1)=1$. Nenhuma mudança ocorre nas demandas até a etapa $t=3$, em que o preço anunciado é $p(3)=3$. Neste preço

$$
\begin{aligned}
& D_{1}(3)=\{1\}, \quad D_{2}(3)=D_{3}(3)=\{2\}, \\
& D_{4}(3)=\{1\} \quad \text { e } \quad D_{5}(3)=\{0,1,2\} .
\end{aligned}
$$

Neste caso $d_{*}(3)=6$ e $n<6$. O preço é novamente aumentado de uma unidade. As demandas dos compradores $p_{1}, \cdots, p_{4}$ não se alteram mas $D_{5}(4)=\{0\}$. Temos ainda $n<d_{*}(4)=6$.

A próxima mudança nas demandas se dará na etapa $t=6$, quando o preço anunciado for $p(6)=6$. Aí

$$
\begin{aligned}
& D_{1}(6)=\{1\}, \quad D_{2}(6)=\{2\}, \quad D_{3}(6)=\{0,1,2\} \\
& D_{4}(6)=\{0,1\} \quad D_{5}(6)=\{0\} .
\end{aligned}
$$


Nesta etapa, $d_{*}(6)=3, d^{*}(6)=6$. Como $n>d_{*}(6)$, existe algum matching $x(6)$ onde $x_{1}(6)+\cdots+x_{5}(6)=\min \left\{n, d^{*}(6)\right\}=5$, $\operatorname{com} x_{j}(6) \in D_{j}(6) \forall j=1, \cdots, 5$, e tal que existe, no máximo, um comprador $j$ com $0<x_{j}(6)<r_{j}$. Na realidade existem dois tais matchings, $x$ e $x^{\prime}$, onde

$$
\begin{aligned}
& x_{1}=1, \quad x_{2}=2, \quad x_{3}=2, \quad x_{4}=0 \quad x_{5}=0 \quad \mathrm{e} \\
& x_{1}^{\prime}=1, \quad x_{2}^{\prime}=2, \quad x_{3}^{\prime}=1, \quad x_{4}^{\prime}=1 x_{5}^{\prime}=0 \text {. }
\end{aligned}
$$

De acordo com a regra de desempate escolhida a priori, se a preferência entre $p_{3}$ e $p_{4}$ recair em $p_{3}$ o leiloeiro escolherá o matching $x$ e caso contrário escolherá $x^{\prime}$. O preço final será $p=p(6)=6$, que é claramente o preço mínimo de equilíbrio.

Teorema 3: Sejam $p$ o preço final obtido no leilão dinâmico e $x$ o matching correspondente. Então $(p, x)$ é um preço de equilíbrio competitivo e $p$ é o preço mínimo de equilibrio.

Demonstração: Se $n \geq d_{*}(0)$ então o leilão termina em $t=0$ e $p=0$ é um preço competitivo, compatível com o matching $x$. Como todo objeto não alocado (se houver) tem preço $0,(p, x)$ é um equilíbrio competitivo e é claro que $p$ é o preço mínimo de equilíbrio.

Passemos então ao caso em que $n<d_{*}(0)$, que implica que $n \notin T(0)$ e $n<d^{*}(0)$. Então, $n \in \bigcup_{t \geq 0} T(t)=\left\{0,1,2, \cdots, d^{*}(0)\right\}$, donde $n \in T(t)$ para algum $t>0$.

Seja $t^{\prime}$ o menor inteiro $t$ tal que $n \in T(t)$. Então, $t^{\prime}>0$ e $n \notin T(t) \forall t<t^{\prime}$. Desta forma, usando que $d_{*}\left(t^{\prime}\right) \leq n \leq d^{*}\left(t^{\prime}\right)=$ $d_{*}\left(t^{\prime}-1\right)$ e que $n \notin T\left(t^{\prime}-1\right)$, decorre que $d_{*}\left(t^{\prime}-1\right)>n$. Portanto, desde que $d_{*}(\cdot)$ é decrescente em $t$, segue que $d_{*}(t) \geq d_{*}\left(t^{\prime}-1\right)>$ $n, \forall t<t^{\prime}$. Logo, $d_{*}(t)>n \forall t<t^{\prime}$. Assim, em toda etapa $t<$ $t^{\prime}$ não é possivel encontrar um matching compativel com $p(t)$, pela Observação 4. Na etapa $t^{\prime}$, como $n \in T\left(t^{\prime}\right)$, existe, por definição 
de $T\left(t^{\prime}\right)$, um matching $x\left(t^{\prime}\right)$ tal que $n=x_{1}\left(t^{\prime}\right)+\cdots+x_{m}\left(t^{\prime}\right)$ e $x_{j}\left(t^{\prime}\right) \in D_{j}(t), \forall j=1,2, \cdots, m$. Portanto, $t^{\prime}$ é a etapa final, $x\left(t^{\prime}\right)=$ $x$ e $p\left(t^{\prime}\right)=p$. Como $p$ é um preço competitivo e todos os objetos são alocados por $x$ implica que $(p, x)$ é um equilíbrio competitivo. Resta mostrar que $p=p\left(t^{\prime}\right)$ é o menor preço de equilíbrio. Para ver isto observe primeiro que, como as avaliaçōes são números inteiros, podemos concluir do Teorema 1 que o preço mínimo de equilíbrio é um número inteiro. Então se $p$ não for o preço mínimo de equilíbrio deve existir um preço de equilíbrio $p^{\prime}$ tal que $p^{\prime}$ é um número inteiro e $p^{\prime}<p$. Visto que $p(t)=t$ para toda etapa $t, p^{\prime}=p(t)$ para algum $t<t^{\prime}$, o que contraria o fato demonstrado acima de que não é possível encontrar um matching compatível com $p(t)$ para $t<t^{\prime}$. Logo, $p$ é o preço mínimo de equilíbrio e a demonstração está completa.

\section{Manipulabilidade do Mecanismo de Leilão Dinâmico.}

Nesta seção mostramos que o mecanismo de leilão dinâmico é manipulável individualmente pelos compradores e oferecemos condiçōes que garantem a sua não manipulabilidade individual por parte desses agentes. Estaremos concentrados no jogo estratégico induzido pelo mecanismo, onde os jogadores são os compradores. Isto é, o jogo que se inicia após o leiloeiro ter anunciado sua regra de desempate e $p(0)$. Em cada etapa do leilão cada comprador deverá declarar qual o seu conjunto de demanda ao preço anunciado pelo leiloeiro. Devido às restriçoes impostas pelo mecanismo aos lances dos ofertantes, de que trata a Observação 5, este procedimento é equivalente a escolher um número $b_{j}$ que fará o papel do valor de reserva do comprador $j$, ao longo de todo o leilão. Assim uma estratégia para o jogador $j$ pode ser pensada como um número $b_{j} \geq 0$. Usaremos a seguinte notação:

- $M=(P, Q, a, r)$ é o mercado original onde, para todo comprador $j, a_{j}$ é o verdadeiro valor de um objeto para $j$. 
- $\sum(M)$ é o conjunto dos matchings ótimos e simples para $M$.

Se $b$ é uma estratégia conjunta para os compradores:

- $M(b)=(P, Q, b, r)$.

- $p_{*}(b)$ é o preço mínimo de equilíbrio para $M(b)$.

- $p(b)$ é o preço obtido no leilão dinâmico, quando os compradores escolhem $b$.

- $\sum(b)$ é o conjunto dos matchings ótimos e simples para $M(b)$.

- $x(b)$ é o matching (ótimo e simples) escolhido pelo leiloeiro no leilão dinâmico quando os compradores selecionam a estratégia conjunta $b$.

Definição 10: Seja $x(b) \equiv x$. O payoff verdadeiro do comprador $j$ associado ao resultado $(p(b), x)$ é: $U_{j}(b, x)=a_{j}-p(b)$ se $x_{j}>0 \mathrm{e}$ $U_{j}(b, x)=0$ se $x_{j}=0$. O payoff total verdadeiro de $j$ associado a $(p(b), x)$ é $x_{j} U_{j}(b, x)$.

O vetor $U(b, x)=\left(U_{1}(b, x), \cdots, U_{m}(b, x)\right)$ é chamado de payoff verdadeiro associado a $(p(b), x)$. Denotaremos por $U^{*}(b, x)$ (resp. $\left.U_{*}(b, x)\right)$ o payoff verdadeiro associado a $\left(p_{*}(b), x\right)$ (resp. $\left.\left(p^{*}(b), x\right)\right)$.

É importante salientar que quando existem vários matchings ótimos e simples em $\sum(b)$, o payoff verdadeiro de um comprador pode depender do matching escolhido, mas este não é o caso quando ele declara sua verdadeira avaliação.

É bem conhecido que no caso especial onde existe somente um objeto para ser leiloado, dizer a verdade é uma estratégia dominante para cada comprador no leilão de segundo preço. Neste caso todos os compradores têm a mesma cota, 1. Além disso, ou o jogador completa a sua cota ou não recebe nenhum objeto. Veremos que o fato da estratégia sincera ser ou não ser dominante para cada jogador 
no leilão dinâmico está relacionado com o fato dos jogadores terem ou não terem a mesma cota e de existir ou não existir algum comprador que receba algum objeto mas não complete a sua cota.

Exemplo 3: (Não é uma estratégia dominante para os compradores revelar suas verdadeiras avaliações no leiläo dinämico, quando os compradores não têm a mesma cota).

10 caso: $B_{x}=\emptyset$, onde $x \in \sum(M)$.

Considere $P=\{1, \cdots, 5\}, r_{1}=2, r_{2}=r_{3}=3, r_{4}=r_{5}=1, n=8 \mathrm{e}$ $a=(8,7,6,5,3)$. O con junto dos preços de equilíbrio deste mercado é dado por $[5,6]$ e o único matching ótimo e simples é $x=(2,3,3,0,0)$. Assim, $B_{x}=\emptyset$.

Se o comprador $j=3$ lança $b_{3}=4$ então o único preço de equilíbrio correspondente a $b=(8,7,4,5,3)$ será $p(b)=4$, e o matching ótimo e simples correspondente será $x(b)=(2,3,2,1,0)$. Se o comprador $j=3$ revela a verdade então o seu payoff total será no máximo $3(6-5)=3$, enquanto o seu payoff total verdadeiro associado a $(p(b), x(b))$ é $2 U_{3}(b, x(b))=2(6-4)=4>3$. Portanto, não é uma estratégia dominante para $j=3$ revelar sua verdadeira avaliação.

20 caso: $B_{x} \neq \emptyset$, onde $\in \sum(M)$.

Considere $P=\{1, \cdots, 5\}, r_{1}=2, r_{2}=r_{3}=3, r_{4}=3, r_{5}=1$, $n=10$ e $a=(8,7,6,5,2)$. O único matching ótimo e simples é $x=(2,3,3,2,0)$. O comprador $j=4$ não preenche a sua cota. Logo, $B_{x}=\{4\}$ e o único preço de equilíbrio deste mercado é 5 .

Se o comprador $j=4$ lança $b_{4}=3$ então o único preço de equilíbrio correspondente a $b=(8,7,6,3,2)$ será $p(b)=3$, e o único matching ótimo e simples será $x(b)=(2,3,3,2,0)$. O payoff total de $j=4$ quando ele revela a verdade é $2(5-5)=0$, enquanto o seu payoff total verdadeiro quando ele lança $b_{4}=3$ é $U_{4}(b, x(b))=$ $2(5-3)=4>0$. Portanto, não é uma estratégia dominante para $j=4$ revelar sua verdadeira avaliação. 
Exemplo 4: (No leilāo dinâmico, nem sempre é uma estratégia dominante para os compradores revelar suas verdadeiras avaliaçōes quando $B_{x} \neq \emptyset$, mesmo que os compradores tenham a mesma cota.)

Considere $P=\{1, \cdots, 4\}, r_{j}=2$, para todo comprador $j, n=5$ e $a=(8,7,6,2)$. O matching ótimo e simples correspondente é $x=(2,2,1,0)$ e, portanto, $B_{x}=\{3\}$. O único preço de equilíbrio deste mercado é 6 .

Se o comprador $j=1$ lançar $b_{1}=3$ então o único preço de equilíbrio correspondente a $b=(3,7,6,2)$ será $p(b)=3$, e o matching ótimo e simples correspondente será $x(b)=(1,2,2,0)$. O payoff total de $j=1$ quando ele revela a verdade é $2(8-6)=4$, enquanto o seu payoff total verdadeiro associado a $(p(b), x(b))$ é $U_{1}(b, x(b))=$ $(8-3)=5>4$. Desta forma não é uma estratégia dominante para $j=1$ revelar sua verdadeira avaliação.

Observação 6: Sejam $P=\{1, \cdots, m\},|Q|=n$ e $r_{j}=c \forall j \in P$. Se $n>m c$ ou se $n$ for um múltiplo de $c$, então é fácil ver que, para todo mercado $M(b)$ e para todo matching $x \in \sum(b), x_{j}=c$ ou $x_{j}=0$. (Use que se $x$ é ótimo e simples então existe no máximo um comprador $j$ tal que $0<x_{j}<r_{j}$ ).

Teorema 4: Se todos os compradores têm a mesma cota c e $n \geq m c$ ou $n$ é um múltiplo de c, então é uma estratégia dominante para os compradores dizer a verdade no leilão dinâmico.

Demonstração: Sejam $j \in P, b=\left(b_{1}, \cdots, b_{j}, \cdots, b_{m}\right)$ e $b^{*}=$ $\left(b_{1}, \cdots, b_{j-1}, a_{j}, b_{j+1}, \cdots, b_{m}\right)$. Denote $x(b)$ por $y$ e $x\left(b^{*}\right)$ por $y^{*}$. Queremos mostrar que $a_{j}$ é uma ótima resposta para $b_{-j}=$ $\left(b_{1}, \cdots, b_{j-1}, b_{j+1}, \cdots, b_{m}\right)$, i.e.,

$$
x_{j}\left(b^{*}\right) U_{j}\left(b^{*}, x\left(b^{*}\right)\right) \geq x_{j}(b) U_{j}(b, x(b))
$$

Revista de Econometria 18 (2) Novembro 1998 
Se $n \geq m c$ então todos os compradores preenchem a sua cota com $y^{*}$ e $y$. Pelo Corolário $2, p_{*}(b)=p_{*}\left(b^{*}\right)=0$. Então, $U_{j}\left(b^{*}, y^{*}\right)=$ $a_{j}-p_{*}\left(b^{*}\right)=a_{j}-p_{*}(b)=U_{j}(b, y)$. Agora use que $y_{j}=y_{j}^{*}=c$ para obter $\left(^{*}\right)$.

Se $n=z c$, para $0<z<m, z$ inteiro, então, pela Observação 6, $z$ compradores preenchem a sua cota e $m-z$ não recebem nenhum objeto, em ambas as alocaçōes. Temos de analisar dois casos.

\section{0 caso: $j$ preenche a sua cota em $y^{*}$.}

Então $U_{j}\left(b^{*}, y^{*}\right)=a_{j}-p_{*}\left(b^{*}\right)=u_{j}\left(b^{*}\right) \geq 0$. Se $j$ não recebe nenhum objeto em $y$, então $U_{j}(b, y)=0 \leq U_{j}\left(b^{*}, y^{*}\right)$ e $\left(^{*}\right)$ segue facilmente. Se $j$ preenche a sua cota em $y$, então usando que $b_{k}^{*}=b_{k} \forall k \neq j$, obtemos que $A_{y}=A_{y *}$ e $C_{y}=C_{y *}$. Pelo Corolário 2, $p_{*}(b)=$ $\max \left\{b_{k} ; k \in C_{y}\right\}=\max \left\{b_{k} ; k \in C_{y^{*}}\right\}=p_{*}\left(b^{*}\right)$, donde $p_{*}(b)=$ $p_{*}\left(b^{*}\right)$. Assim, $U_{j}(b, y)=a_{j}-p_{*}(b)=a_{j}-p_{*}\left(b^{*}\right)=U_{j}\left(b^{*}, y^{*}\right)$. Agora use que $y_{j}=y_{j}^{*}$ para obter $\left({ }^{*}\right)$.

\section{0 caso: $j$ não recebe nenhum objeto em $y^{*}$.}

Então $y_{j}^{*}=0$ e $U_{j}\left(b^{*}, y^{*}\right)=0$. Necessitamos apenas checar o caso em que $j$ preenche a sua cota em $y$, já que no outro caso $\left(^{*}\right)$ vale trivialmente. Assim, se $y_{j}=c$, então como exatamente $z$ compradores preenchem a sua cota em $y$ e $y^{*}$, existe um comprador, $k$, tal que $k$ preenche a sua cota em $y^{*}$ e não recebe nenhum objeto em $y$. Isto é, $A_{y}=\left(A_{y *}-\{k\}\right) \cup\{j\}$ e $C_{y}=\left(C_{y *}-\{j\}\right) \cup\{k\}$. Como $k \in A_{y *}$, implica que $b_{k} \geq b_{t} \forall t \in C_{y^{*}}-\{j\}$ e $b_{k} \geq a_{j}$. Da primeira implicação segue que $b_{k} \geq b_{t} \forall t \in C_{y}$, o que significa que $b_{k}=\max \left\{t ; t \in C_{y}\right\}=p_{*}(b)$. Da segunda implicação segue que $a_{j}-b_{k} \leq 0$, donde $a_{j}-p_{*}(b) \leq 0$ e, portanto, $U_{j}(b, y)=a_{j}-b_{k} \leq 0$. Logo, $y_{j}^{*} U_{j}\left(b^{*}, y^{*}\right)=0 \geq y_{j} U_{j}(b, y)$, o que mostra $\left(^{*}\right)$ e a demonstração está completa. 


\section{Conclusão.}

Apresentamos, inicialmente, um mercado com um único vendedor onde compradores querem comprar objetos idênticos, até uma certa cota. Cada comprador tem um preço máximo que estaria disposto a pagar por um objeto; o vendedor tem um preço mínimo pelo qual aceitaria vender qualquer dos objetos. Qualquer comprador pode efetuar uma transação com o vendedor se ambos concordarem e ninguém é compelido a comprar ou vender. Os agentes podem comunicar-se uns com os outros. Ofertas e contra-ofertas são feitas terminando com uma alocação dos objetos para os compradores, que respeita as cotas de cada agente, e com um preço para os objetos. É razoável imaginar que uma transação entre um comprador e o vendedor ocorrerá somente quando ambos os agentes estiverem certos de que nada mais favorável existe para eles no mercado.

Que transaçoes podemos predizer que ocorrerão?

Esta é a primeira e fundamental pergunta economicamente natural que emerge de um tal jogo de mercado. Não podemos predizer que algum comprador comprará algum objeto por um preço maior que o seu preço de reserva. Da mesma forma o vendedor não venderá nenhum objeto por um preço inferior ao preço minimo de venda. Não podemos esperar que algum comprador compre um número de objetos inferior ao seu limite, se o preço dos objetos for inferior ao máximo que estaria disposto a pagar: Antes de que a transação fosse concluída o comprador of ereceria ao vendedor um preço maior do que os outros estão pagando para preencher toda a sua cota.

Estamos diante de um jogo cooperativo e portanto as regras do jogo não especificam os detalhes de como as transações são feitas. 
Identificado o conceito solução adequado para este jogo como sendo o de equilíbrio competitivo, ${ }^{3}$ a segunda pergunta que gostaríamos de fazer é se esses equilíbrios sempre existem. Dado que a resposta é afirmativa o passo seguinte é saber como obtê-los. É facil imaginar que um mercado descentralizado como o exposto acima nem sempre será eficiente, apresentando falhas na sua organização. A idéia então é usar um mecanismo de compra e venda centralizado que produza equilíbrios competitivos. Neste ponto estabelecemos uma ponte entre jogos cooperativos e não cooperativos. É altamente desejável para um mecanismo que ele seja não manipulável ou à prova de estratégia. Então a pergunta é se existe um tal mecanismo. Com as hipóteses de que todos os compradores têm a mesma cota e o número de objetos é um múltiplo dessa cota ou é maior que a quantidade total das cotas, provamos que o leilão ascendente sugerido aqui é à prova de estratégia. (Considerando que o jogo começa depois de conhecido o preço de reserva do vendedor). Além disso o preço dos objetos obtido com esse leilão é o menor preço de equilíbrio competitivo e os compradores só necessitam conhecer o seu próprio preço de reserva.

Modernamente, a análise de muitas situaçōes econômicas, modeladas tradicionalmente como um jogo não cooperativo, não pode ignorar as consequências dos indivíduos operarem em grupos. A investigação dessas conseqências requer o uso de ferramentas da teoria dos jogos cooperativos. Os nossos resultados ilustram o fato de que, o que é relevante para a escolha da ferramenta na modelagem e análise de uma situação econômica não é o rótulo que lhe damos, mas são as

\footnotetext{
${ }^{3} \dot{E}$ fácil ver que os preços dos objetos podem ser diferentes nos vetores-payoff do núcleo e que este contém propriamente o conjunto dos vetores-payoff correspondentes a preços de equilibrio. $O$ núcleo seria o conceito soluçāo adequado para este mercado se nāo estivéssemos nos restringindo aos vetores-payoff onde os preços dos objetos sāo iguais.
} 
perguntas que emergem dela. Para responder a algumas usamos as ferramentas dos jogos cooperativos e para responder a outras usamos as ferramentas dos jogos não cooperativos.

No mercado tratado aqui, que é muito simples, nenhum resultado é surpreendente. Todos os teoremas são intuitivos e óbvios. Talvez por isto eles nunca tenham antes merecido uma demonstração formal. A surpresa, porém, foi que no nosso caso a formalização do óbvio e intuitivo não foi tão direta e simples como prometia ser. Ela exigiu uma maturidade matemática não comumente encontrada nos não matemáticos, embora os argumentos matemáticos que impregnam as demonstraçōes não tenham requerido, para o seu entendimento, nenhum ferramental matemático que qualquer estudante de graduação de Economia não possua. Na verdade nem mesmo conhecimento de Cálculo foi pressuposto. Por isso, estes alunos serão capazes de acompanhar, passo a passo, qualquer das nossas demonstraçōes. Acreditamos que este trabalho possa ser útil para um professor de Matemática interessado em ilustrar para esses estudantes o fato de que Matemática não é sempre fórmulas, figuras, números e termos complicados.

Submetido em Maio de 1999. Revisado em Setembro de 1999.

\section{Referências Bibliográficas}

Ausubel, L. 1997. "An efficient ascending-bid auction for multiple objects". Working Paper, 97-06.

Crawford, V.P \& Knoer, E.L. 1981. "Job matching with heterogeneous firms and workers". Econometrica 49:437-450.

Demange, G. 1982. "Strategyproofness in the assignment market game". Preprint. Paris: École Polytechnique, Laboratoire dÉconometrie. 
\& Gale, David. 1985. "The strategy structure of twosided matching markets". Econometrica 53:873-883.

; Gale, David \& Sotomayor, Marilda. 1986. "Multi-item auctions". J.P.E. 94:863-872.

Leonard, Herman B. 1983. "Elicitation of honest preferences for the assignment of individuals to positions". J.P.E. 91:461-479.

Roth, A. \& Sotomayor, Marilda. 1990. "Two-sided matching. A study in game theoretic modeling and analysis". Econometric Society Monograph Series 18. Cambridge University Press.

Rustichini, A.; Satterthwaite, Mark \& Williams, Steven. 1994. "Convergence to efficiency in a simple market with complete information". Econometrica 62(5):1041-1063.

Shapley, Lloyd S. \& Shubik, Martin. 1972. "The assignment game I: The core". International Journal of Game Theory 1(2):111-130.

Sotomayor, Marilda. 1992. "The multiple partners game". Em Majumdar, M. ed., Equilibrium and Dynamics: Essays in Honor to David Gale, 322-336. Macmillian.

- 1999a. "The lattice structure of the set of stable outcomes of the multiple partners assignment game". International Journal of Game Theory, a aparecer.

Vickrey, W. 1961. "Counterspeculation, auctions and competitive sealed tenders". Journal of Finance 16:8-37.

Wilson R. 1977. "A bidding model of perfect competition". Review of Economic Studies 44(3):511-518. 